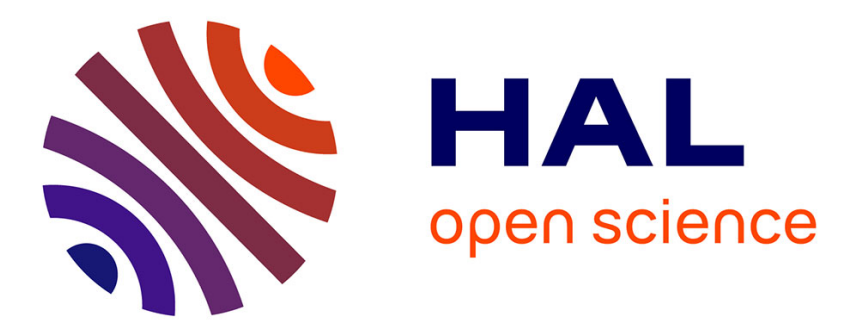

\title{
Acyl-Imidazoles A Privileged Ester Surrogate for Enantioselective Synthesis
}

J. Lauberteaux, D. Pichon, Olivier Baslé, Marc Mauduit, Renata Marcia de Figueiredo, J.-M. Campagne

\section{- To cite this version:}

J. Lauberteaux, D. Pichon, Olivier Baslé, Marc Mauduit, Renata Marcia de Figueiredo, et al.. AcylImidazoles A Privileged Ester Surrogate for Enantioselective Synthesis. ChemCatChem, 2019, 11 (23), pp.5705-5722. 10.1002/cctc.201900754 . hal-02181832

\section{HAL Id: hal-02181832}

\section{https://hal-univ-rennes1.archives-ouvertes.fr/hal-02181832}

Submitted on 7 Nov 2019

HAL is a multi-disciplinary open access archive for the deposit and dissemination of scientific research documents, whether they are published or not. The documents may come from teaching and research institutions in France or abroad, or from public or private research centers.
L'archive ouverte pluridisciplinaire HAL, est destinée au dépôt et à la diffusion de documents scientifiques de niveau recherche, publiés ou non, émanant des établissements d'enseignement et de recherche français ou étrangers, des laboratoires publics ou privés. 


\section{Acyl-Imidazoles: A Privileged Ester Surrogate for Enantioselective Synthesis}

Jimmy Lauberteaux, ${ }^{[\mathrm{a}]}$ Delphine Pichon, ${ }^{[\mathrm{b}]}$ Olivier Baslé,${ }^{[\mathrm{c}]}$ Marc Mauduit, ${ }^{[\mathrm{b}]}$ Renata Marcia de Figueiredo, ${ }^{*[a]}$ and Jean-Marc Campagne ${ }^{*[a]}$

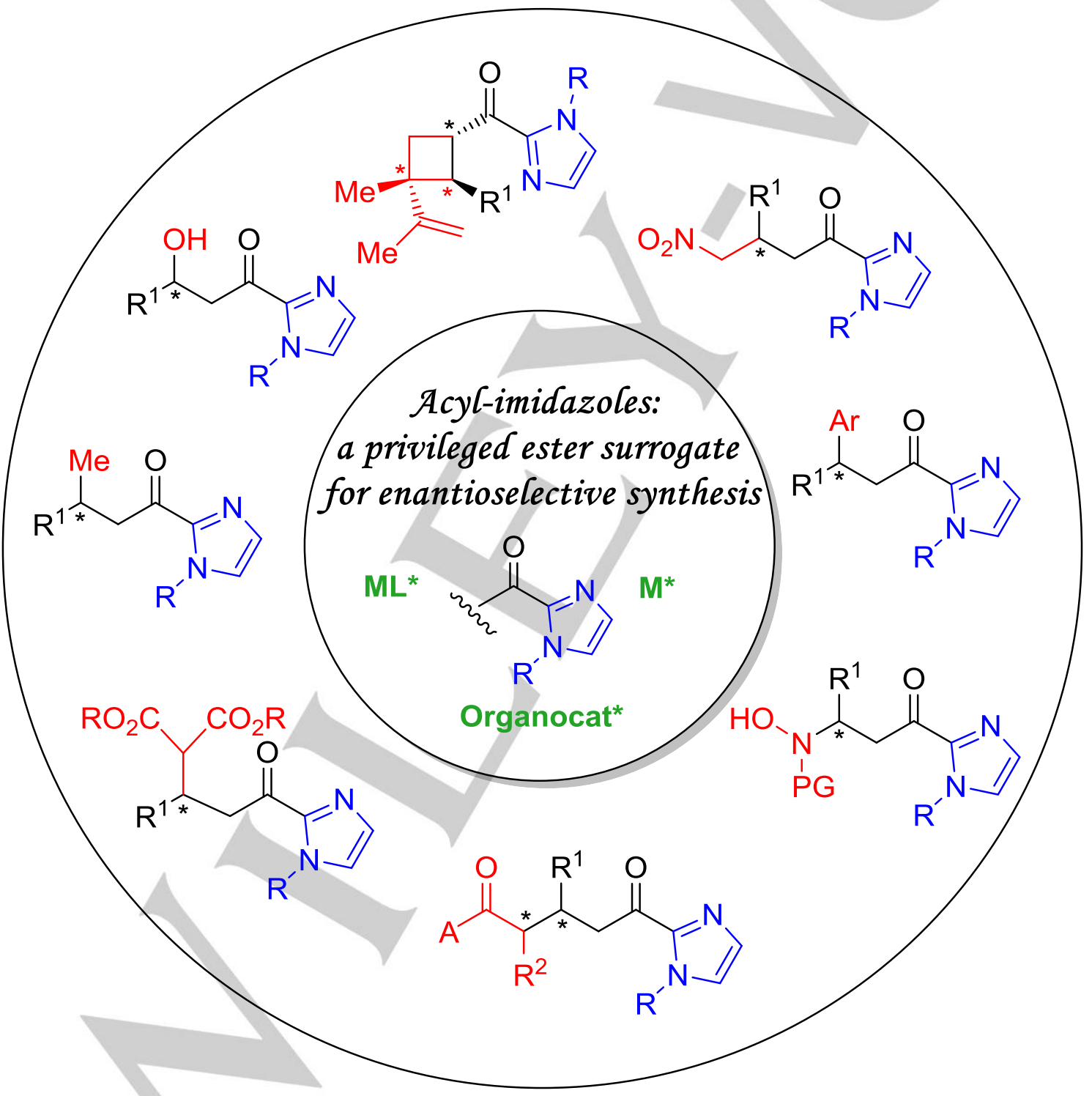


Abstract: Since the first report by Evans in asymmetric FriedelCrafts reactions, the use of acyl-imidazoles has blossomed as powerful ester/amide surrogates. The imidazole scaffold indeed displays stability and special activation features allowing both better reactivity and selectivity in traditional ester/amide functionalizations: $\alpha$-(enolate chemistry), $\beta$-(conjugate additions), $\alpha, \beta$-(cycloadditions) or $\gamma / \delta$-(vinylogous). An overview of the contemporary and growing interest in acyl-imidazoles in metaland organo-catalyzed transformations (bio-hybrid catalytic systems will be fully described in a back-to-back Minireview) will be highlighted. Moreover, post-functionalization expediencies are also going to be discussed in this Minireview.

\section{Introduction}

Esters/amides are essential in the organic chemists tool-box due to their easy transformation via $\alpha$-(enolate chemistry), $\beta$ (Michael and Friedel-Crafts-type additions), $\alpha, \beta$-(Cycloadditions) or $\gamma / \delta$-(vinylogous) functionalizations.

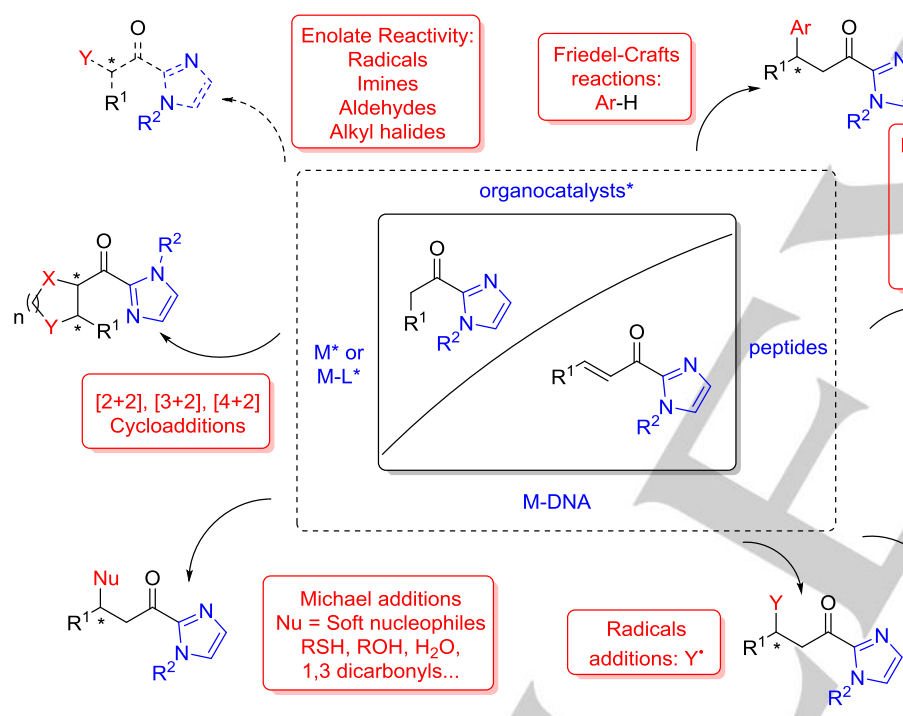

Figure 1. Acyl-imidazoles: a privileged scaffold for enantioselective synthesis.

[a] J. Lauberteaux, Dr. R. M. de Figueiredo, Prof. Dr. J.-M. Campagne ICGM -UMR 5253, Univ Montpellier, CNRS, ENSCM

240 Avenue du Professeur Emile Jeanbrau

34296 Montpellier Cedex 5 (France)

E-mail : renata.marcia_de_figueiredo@enscm.fr jean-marc.campagne@enscm.fr

[b] D. Pichon, Dr. M. Mauduit

Univ Rennes, Ecole Nationale Supérieure de Chimie de Rennes, CNRS, ISCR UMR 6226, F-35000 Rennes, France

11 Allée de Beaulieu, CS 50837, 35708 Rennes Cedex 7 (France)

[c] Dr. O. Baslé

Laboratoire de Chimie de Coordination, CNRS, UPR 8241,

205 Route de Narbonne, 31077 Toulouse Cedex 4 (France)

ORCID identification number(s):

Renata Marcia de Figueiredo: 0000-0001-5336-6071

Jean-Marc Campagne: 0000-0002-4943-047X

Marc Mauduit: 0000-0002-7080-9708

Olivier Baslé: 0000-0002-4551-473X
The lower intrinsic reactivity of esters (amides) compared to ketones has paved the way for the development of ester surrogates. The preeminent features for such surrogates are: i) higher stability; ii) enhanced reactivity (compared to esters/amides); iii) improved stereoselectivities due to privileged modes of coordination; iv) easy transformation not only towards their parent ester/amide but also to ketones, aldehydes... under mild conditions. Among the wide range of ester surrogates (oxazolidinones, acylphosphonates, imides, pyrrolidinones...), acyl-imidazoles have emerged as privileged partners in catalytic and asymmetric transformations (Figure 1). Indeed, more than $90 \%$ of the papers have been published after 2010 . The salient features of acyl-imidazoles are:

- The possibility to form a chelate with metals, via double coordination, leading to a better anchoring of metals and an increased structural transition state organization, as illustrated with the successful use of a wide range of metal-based catalysts: $\mathrm{Cu}, \mathrm{Pd}, \mathrm{Rh}, \mathrm{Ir}, \mathrm{Ru}, \mathrm{Ce}, \mathrm{Sn}$...

- The stability of the metal complex, notably with copper salts, in the presence of water, allowing the use of complex macromolecules such as DNA or proteins as the source of chirality.

- An easy introduction of the imidazole moiety and easy post-functionalization of the acyl-imidazole to common carbonyl analogs: aldehydes, ketones, esters, amides, amines etc.

- A good structural interaction in the presence of organocatalysts, affording high stability (privileged $\pi$-stacking), reactivity and selectivity.

- Acyl-imidazoles are more electronwithdrawing groups compared to esters and other ester-surrogates and stable towards hydrolytic cleavage.

\subsection{Synthesis of acyl-imidazoles derivatives}

The acyl-imidazole derivatives, first reported by Okamato, ${ }^{[1]}$ are readily accessible from the corresponding aldehydes or pyrrolidino/Weinreb amides, as illustrated in scheme 1. $\alpha, \beta$-Unsaturated derivatives can be obtained using the above strategies but are also easily accessible through Wittig or HWE reagents (Scheme 2). Alternatively, $\alpha, \beta$-unsaturated aromatic derivatives can be obtained on large scale in a single step by an aldol condensation between 2-acetyl-1-methylimidazole and the corresponding aromatic aldehyde.

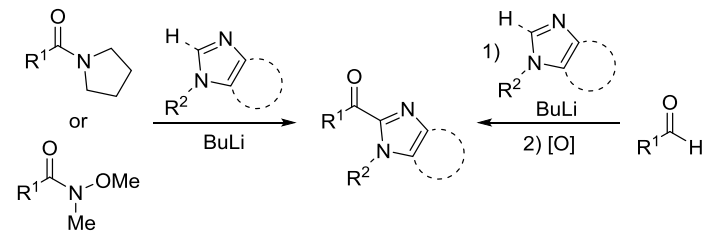

Scheme 1. Synthesis of acyl-imidazoles by Okamoto and co-workers. 


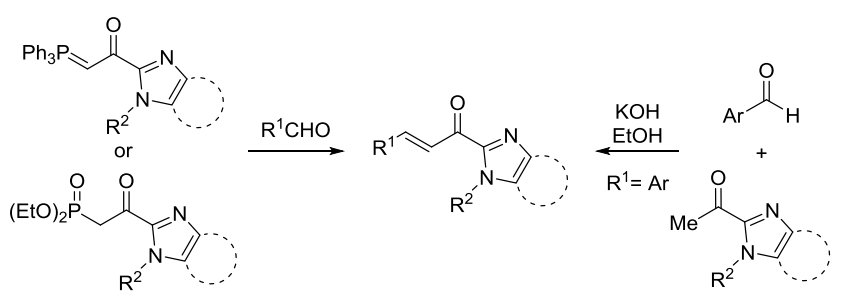

Scheme 2. Synthesis of $\alpha, \beta$-unsaturated acyl-imidazoles.

\subsection{Easy post-functionnalization reactions}

After $\mathrm{N}$-alkylation of the imidazoyl group, the resulting imidazolium salt $\mathbf{A}$ can act as an excellent leaving group enabling an easy post-transformation into a wide range of carbonyl derivatives (Scheme 3). ${ }^{[2-4]}$ Carboxylic acids B, esters $\mathbf{C}$ and amides $\mathbf{D}, \beta$-oxoesters or 2-carbonyl malonates (and derivatives) $\mathbf{H}$ can be directly obtained by the reaction of the corresponding nucleophiles to the $N-R^{2}$ imidazolium salts. Alternatively, ketones $\mathbf{E}$ and aldehydes $\mathbf{F}$ can be obtained using a different strategy by first treating the acyl-imidazole with the corresponding nucleophile (Grignard reagent or hydride source). The resulting imidazole moiety is then alkylated and finally a base-promoted elimination unveils the ketone (or aldehyde) product. In the synthesis of aldehydes, the use of an excess of an amine ( $\varepsilon$-amino caproic acid, glycine...) is essential to prevent extensive formation of cross-aldol products through the formation of a less reactive imine. ${ }^{[5]}$ At the end of the reaction, an acidic work-up is carried out to finally reveal the aldehyde functionality. The formation of such imine intermediates was next used to promote a one-pot reductive amination enabling the formation of secondary amines $\mathbf{G}$ from acyl-imidazoles. ${ }^{[6]}$

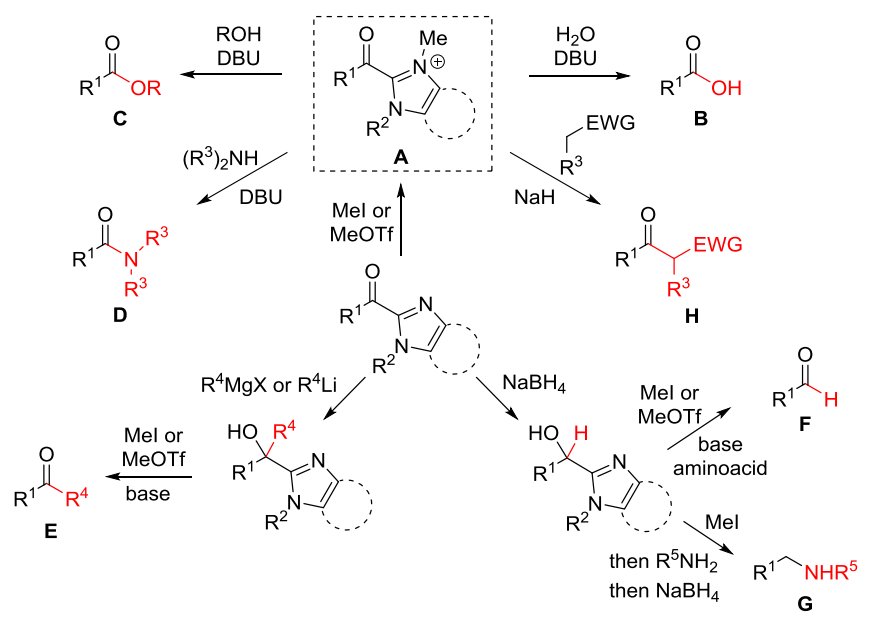

Scheme 3. Post-functionnalizations of acyl-imidazole derivatives.
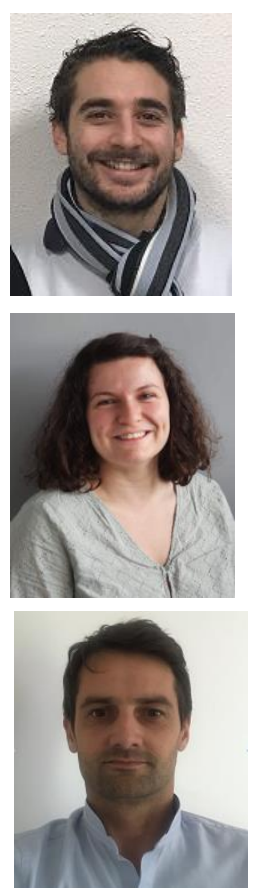

Jimmy Lauberteaux received his MSc from the Ecole Nationale Supérieure de Chimie de Rennes (ENSCR). He is currently carrying his PhD in the team of Prof. J.-M. Campagne and Dr. R. M. de Figueiredo with the aim of developing metalcatalyzed asymmetric catalysis for the synthesis of natural products.

Delphine Pichon received her Master degree from the Ecole Nationale Supérieure de Chimie de Rennes (ENSCR) in 2017. She is currently doing her $\mathrm{PhD}$ within Dr. Marc Mauduit's group related to the design of helicenic N-Heterocyclic Carbenes ligands for the asymmetric catalysis.

Olivier Baslé completed his Master degree under the supervision of Prof. P.H Dixneuf at the university of Rennes in 2006 and obtained his $\mathrm{PhD}$ degree in 2009 at McGill University under the guidance of Prof. C.-J. Li. After postdoctoral studies with Prof. J. Rodriguez and $T$. Constantieux in Marseille and Dr. D. Bourrisou in Toulouse, he was appointed CNRS researcher in 2011 at ENSC-Rennes. In 2018, he joined the CNRS Laboratory of Coordination Chemistry (LCC) in Toulouse. His research program focuses on the development of selective catalytic transformations using $\mathrm{N}$ Heterocyclic Carbene-Metal complexes.

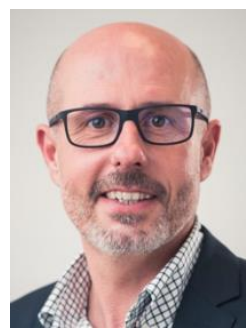

Marc Mauduit was appointed CNRS researcher in 2001 at the ENSC-Rennes (UMR 6226 «Institute of Chemical Sciences of Rennes »). His research interest focuses on the development of $\mathrm{N}$ Heterocyclic Carbene Metal complexes for highly selective catalytic transformations (rutheniumcatalyzed olefin metathesis and copper-catalyzed cross-coupling) as well as for biological activities.

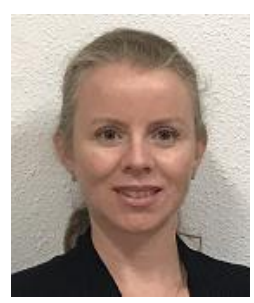

Renata Marcia de Figueiredo was appointed CNRS researcher in 2008 at the ICGM-ENSCM. Her research interests include the development and the application of catalytic asymmetric methodologies to the total synthesis of natural products and biologically active targets as well as peptide synthesis.

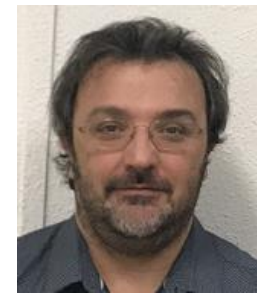

Jean-Marc Campagne was appointed CNRS researcher at the Institut de Chimie des Substances Naturelles (ICSN) in Gif-sur-Yvette in 1998. In 2005, he moved to the ENSCM where he currently holds the position of professor. His current interests concern the development of catalytic asymmetric transformations and their application to the total synthesis of natural products. 


\subsection{One functionality enabling diverse modes of activation}

The potential of acyl-imidazoles as bidentate conjugate acceptors in enantioselective synthesis was early recognized by Evans in Friedel-Crafts (FC) reactions using scandium salts in the presence of chiral ligands. ${ }^{[5]}$ The concept in which the acylimidazole is activated through a chelate with a transition metal equipped with a chiral ligand could next be extended to a wide variety of metals and reactions (section 2). Acyl-imidazoles also proved excellent partners with chiral-at-metal (Ir, Rh) complexes notably enabling photoredox enantioselective catalysis (section 3). Playing on other modes of activation, acyl-imidazole derivatives have also been used in organocatalyzed reactions (section 4). Finally, thanks to the solid coordination of acylimidazoles to copper derivatives, and the stability of such complexes in water, bio-hybrid catalysts (DNA, metallo-enzymes, peptides) were successfully used in various reactions (section 5).

\section{Classical Transition Metal catalysis $\left(M+L^{*}\right)$}

\section{1. $\beta$-Functionalization through 1,4 -additions (Friedel-} Crafts; soft nucleophiles; organometallic reagents...)

\subsubsection{Friedel-Crafts type additions}

As previously mentioned, the first report describing the use of $\alpha, \beta$-unsaturated 2-acyl-imidazoles 1 in enantioselective catalysis was made by Evans and coworkers in $2005 . .^{[5]}$ The chiral bis(oxazolinyl)pyridine (pybox)-scandium(III) triflate complex I demonstrated excellent catalytic activity and high chiral induction (up to $98 \%$ ee) in the FC alkylation of a series of indole derivatives with 1 (Scheme 4). Also illustrated in the alkylation of 2-methoxyfuran and pyrrole, the authors could evidence the beneficial role of the sterically demanding imidazole $\mathrm{N}$-isopropyl substituent in the level of reaction enantioselectivity. Using the same catalytic system, Evans and co-workers extended their investigation in the alkylation of pyrroles (up to $99 \%$ ee) highlighting the synthetic potential of the acyl-imidazole function. ${ }^{[7]}$ The enantioenriched 2,3-dihydro- $1 H$-pyrrolizine 3 is accessible thanks to a one-pot methylation/cyclization of the pyrrole alkylated product leading after reduction to the (+)heliotridane alkaloid $4 .{ }^{[4]}$

\subsubsection{Soft nucleophiles additions}

In the field of catalysis through metal complexes bearing chiral ligands, and among pioneering works in this area, Roelfes, Liskamp and co-workers published the enantioselective $\mathrm{Cu}$ catalyzed Michael addition of malonate to $\mathbf{1}$ using a triazacyclophane-based ligand. ${ }^{[8]}$ Unfortunately, only modest enantioselectivity $(24 \%$ ee $)$ was obtained. It should be emphasized that much higher selectivities have been observed, by the same authors, using bio-hybrid catalysts (see section 5). In 2015, Wang and co-workers reported the asymmetric Michael addition of $5 \mathrm{H}$-oxazol-4-ones 5 on 1. $^{[9]}$ Using the dinuclear zinc-
ProPhenol complex II with achiral phenol derivative as co-ligand, they were able to access a wide range of $\beta$-functionalized acylimidazoles 6 with excellent diastereo- and enantioselectivities (Scheme 5).
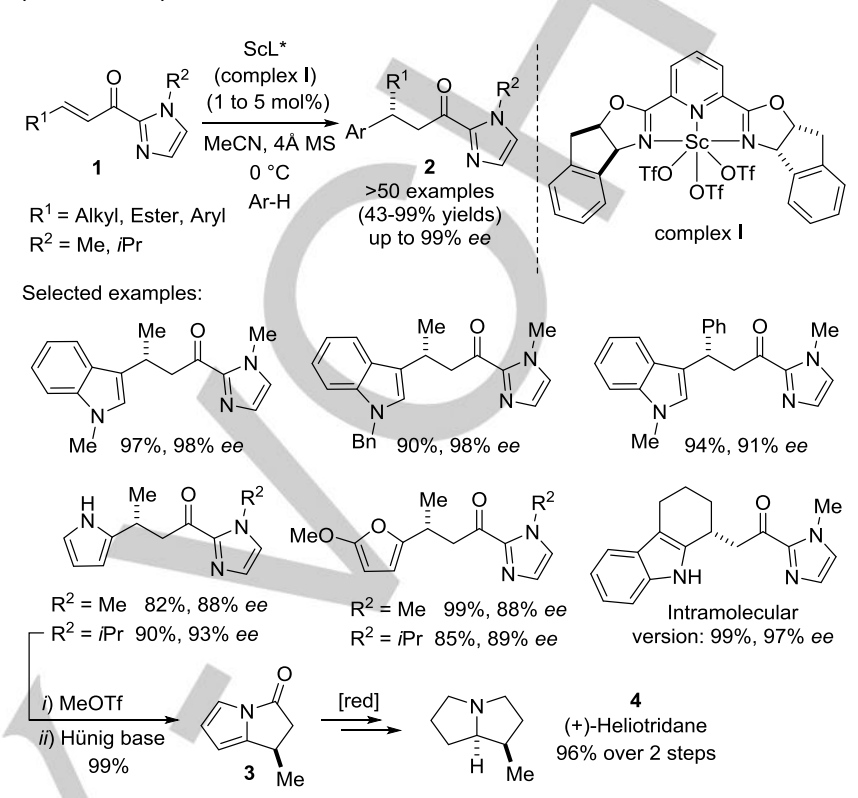

Scheme 4. Sc(III)-complex on FC additions to $\alpha, \beta$-unsaturated acyl-imidazoles.

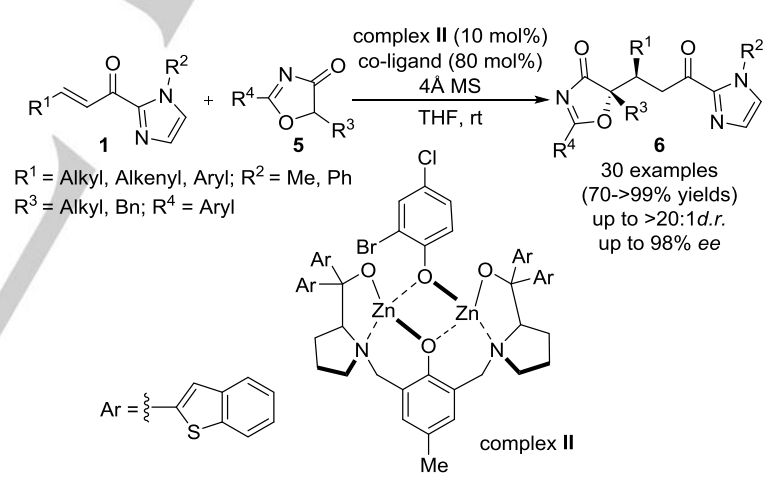

Scheme 5. Dinuclear Zn-ProPhenol complex II on Michael additions.

\subsubsection{Addition of organometallic compounds}

In the area of modern enantioselective catalysis, the 'transition metal-catalyzed' asymmetric conjugate addition (ACA) of organometallic reagents to electron deficient alkenes has emerged as an efficient methodology for the selective formation of $\mathrm{C}-\mathrm{C}$ bonds. ${ }^{[10]}$ Important breakthroughs were accomplished in this field, offering a versatile toolbox to the organic chemist to tackle manifold issues often encountered in the total synthesis of complex natural molecules. ${ }^{[10 \mathrm{~b}]}$ Curiously, among the myriad of Michael acceptors, the acyl-imidazole function as electronwithdrawing group (EWG) was scarcely investigated in ACA involving organometallic reagents. 


\subsubsection{Addition of alkyl boron reagents}

Sawamura, Ohmiya and co-workers were the first to report the copper-catalyzed enantioselective conjugate addition of alkyl borons to 1. After a previous successful study involving the achiral IMes $/ \mathrm{CuCl}$ catalytic system and various in situ generated functionalized alkyl boranes (alkyl-9-BBN) readily available via alkene hydroboration, ${ }^{[11 \mathrm{a}]}$ they developed an asymmetric version by screening a set of chiral NHC ligands (Scheme 6) ${ }^{[11 \mathrm{~b}]} \mathbf{L 1}$ appeared the most efficient toward $\alpha, \beta$-unsaturated 2-acyl-1methylbenzimidazoles 7 affording the desired 1,4-adducts 8 in excellent yields and remarkable high enantioselectivities. Advantageously, a wide range of functional groups are tolerated. Moreover, thanks to the 2-acyl-imidazole function, adducts 8 could be readily converted into the corresponding esters and alcohols in good yields without racemization.
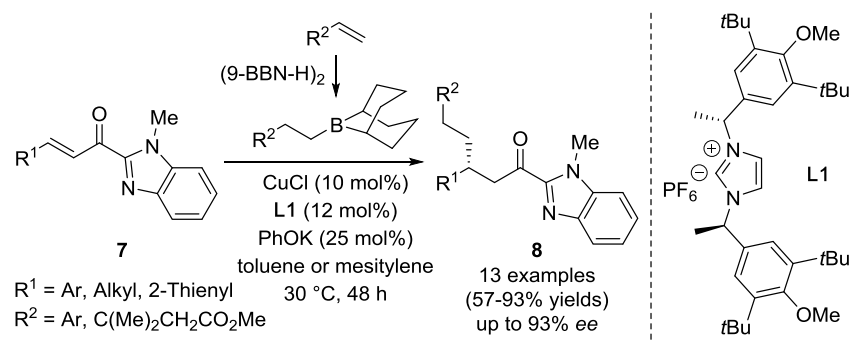

Scheme 6. Enantioselective conjugate addition of alkyl boranes to $\alpha, \beta$ unsaturated 2-acyl 1-methylbenzimidazoles catalyzed by a Cu-NHC complex.

\subsubsection{Addition of dialkylzinc and Grignard reagents}

Numerous biological active molecules feature a methyl stereogenic center and the enantioselective transfer of a methyl group remains a real challenge. In 2015, Mauduit, Campagne and co-workers proposed a highly selective addition of dimethylzinc to acyl-imidazole Michael acceptors as a versatile synthetic platform to build many desirable chiral building-blocks and related natural products (Scheme 7) ${ }^{[6]}$ After a screening of various chiral ligands in presence of $\mathrm{Cu}(\mathrm{OTf})_{2}$ complex, NHC precursor L2 was the most efficient to promote the 1,4-addition of $\mathrm{Me}_{2} \mathrm{Zn}$ to various $\alpha, \beta$-unsaturated 2-acyl-imidazoles 1 with good yields and enantioselectivities. Notably, poor selectivity $(<20 \%$ ee) was observed with diethyl- and diphenyl-zinc. The synthetic potential of the acyl-imidazole moiety has been illustrated through the 3-step synthesis of (+)-ar-turmerone 10 and odorant molecules $\mathbf{1 1}$ and $\mathbf{1 2}$ which were isolated in good overall yields from the corresponding enantioenriched 1,4adducts. Moreover, the rapid access to the aldehyde function allowed an iterative process leading to 1,3-deoxypropionate skeletons $9 a$ and $9 b$ in good overall yields and excellent diastereomeric ratios.

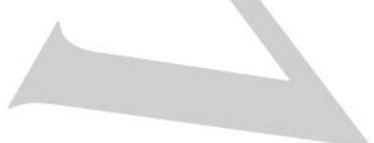

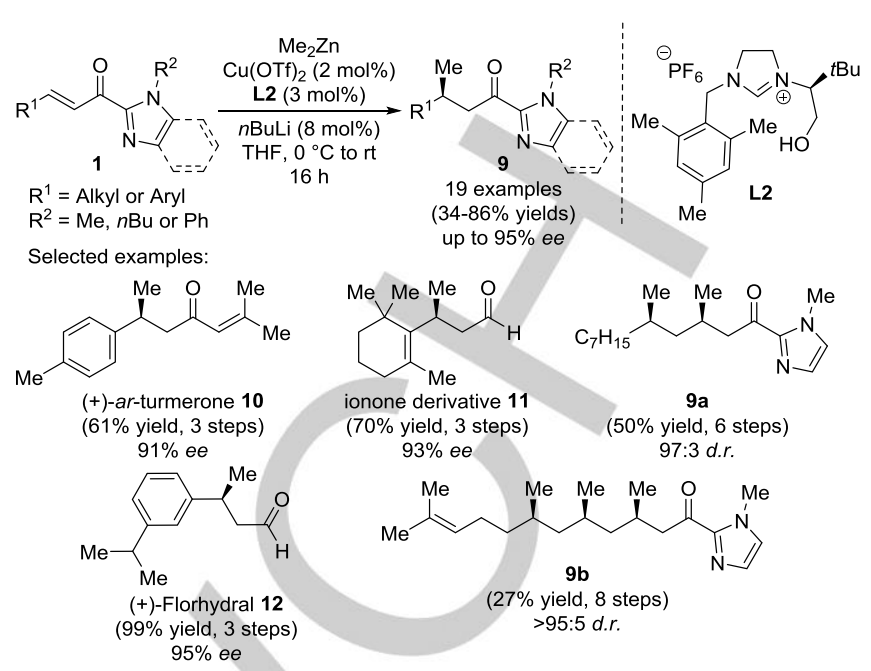

Scheme 7. Cu-catalyzed enantioselective conjugate addition of dimethylzinc to $\alpha, \beta$-unsaturated 2-acyl 1-methylimidazole.

The methodology was extended to di- and trienic 2-acyl-1methylimidazole substrates 13 . As depicted in scheme 8 , the reaction proceeds with a remarkable 1,4 regioselectivity (vs 1,6 and 1,8 ) with high enantio discriminations. Interestingly, DFT calculations highlighted the crucial role of the $\mathrm{N}$-imidazole heterocycle towards the 1,4-regioselectivity. ${ }^{[6]}$

\subsubsection{Mukaiyama-Michael additions}

Substrates 1 were also employed in modified MukaiyamaMichael reaction. Preliminary work on this purpose was done by Doyle's group where the addition of enolates from 2-diazo-3butanoates 15 under $\mathrm{Cu}(\mathrm{II})$-box ligand catalysis afforded functionalized diazoacetoacetates $\mathbf{1 6}$ in good yields and enantioselectivities (Scheme 9a). ${ }^{[12]}$ Following on this seminal report, $\gamma$-butenolides 18 were prepared through the use of silyloxyfurans 17 as substrates under either $\mathrm{Sc}(\mathrm{III})$ or $\mathrm{Er}(\mathrm{III})$ indapybox catalysis (Scheme 9b). ${ }^{[13]}$ Interestingly, by keeping the same chiral ligand, a simple switch in the metal-center from Sc(III) to In(III) resulted in a complete reversal of the enantioselectivity. This could be observed during the synthesis of 1,5-diketones. ${ }^{[14]}$

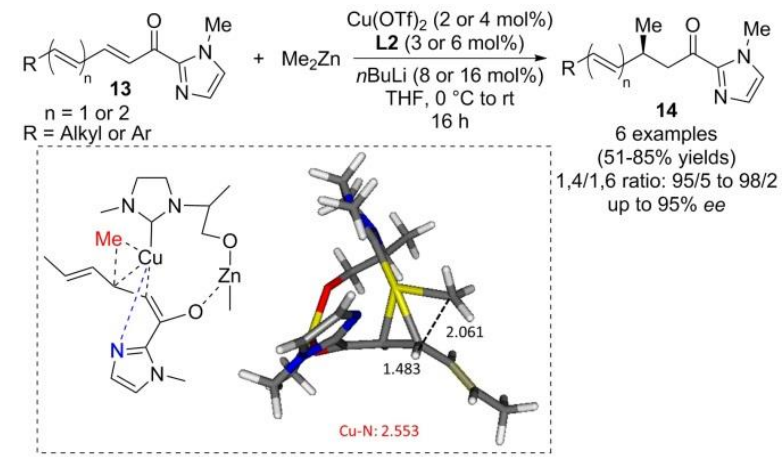

Scheme 8. 1,4-Regioselective asymmetric conjugate addition of dimethylzinc to poly-unsaturated 2-acyl-1-methylimidazoles. Adapted with permission from Ref. 6b. Copyright 2016 John Wiley \& Sons. 

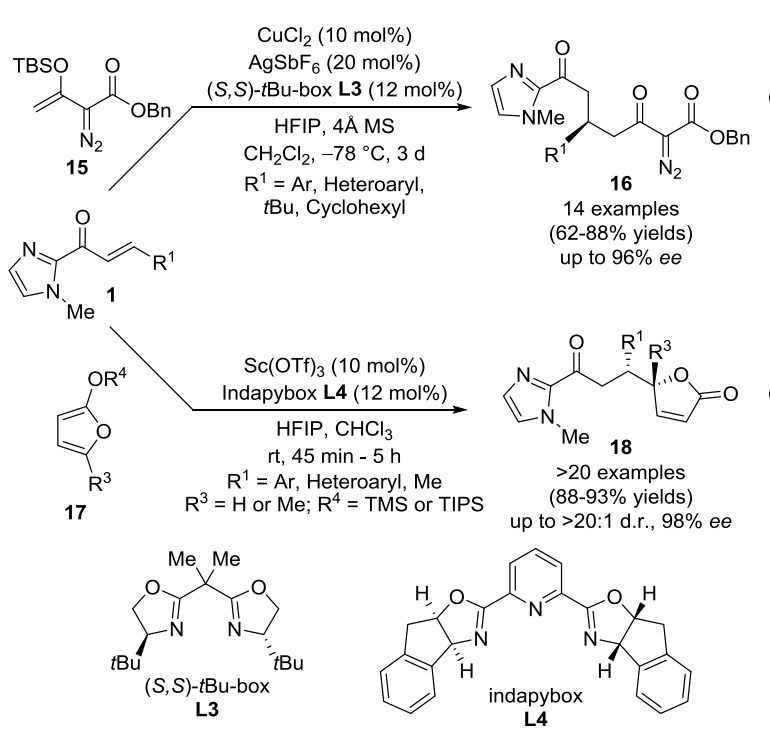

Scheme 9. Mukaiyama-Michael addition to $\alpha, \beta$-unsaturated acyl-imidazoles.

\subsection{Cycloadditions}

\subsection{1. $[3+2]$}

Enantioselective nitrone 1,3-dipolar cycloadditions catalyzed by bis(oxazolinyl)pyridine-Ce(IV) triflate complexes was described in 2006 by Evans and co-workers (Scheme 10). ${ }^{[15]}$ The adducts are flexible building blocks for easy transformation into $\beta$ 'hydroxy- $\beta$-amino acid derivatives 21 . One similar transformation was reported in 2015 by Meggers and co-workers using chiral Ir(III) complex (see section 3). ${ }^{[16]}$

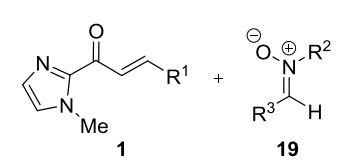
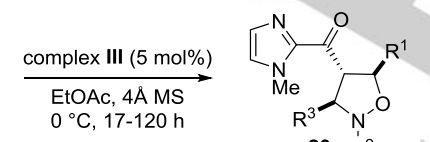

$\mathrm{R}^{1}=\mathrm{Me}, \mathrm{Et}, \mathrm{Pr}, n-\mathrm{Bu}, \mathrm{Ph}, \mathrm{CO}_{2} \mathrm{Et}$ $\mathrm{R}^{2}=\mathrm{Me}, \mathrm{Ph}, \mathrm{Bn} ; \mathrm{R}^{3}=\mathrm{Ar}, \mathrm{Et}, \mathrm{Cy}$

$$
\begin{gathered}
0{ }^{\circ} \mathrm{C}, 17-120 \mathrm{~h} \\
15 \text { examples } \\
(72-99 \% \text { yields) } \\
\text { endo:exo (up to >99:1) }
\end{gathered}
$$
up to $>99 \%$ ee

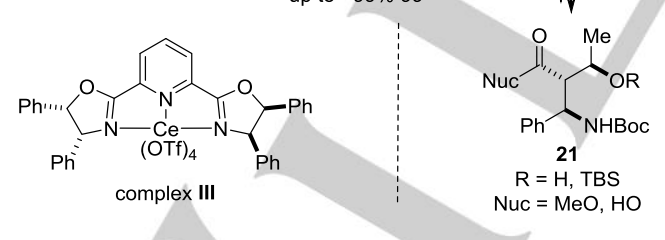

Scheme 10. Enantioselective 1,3-dipolar cycloadditions of 1 with nitrones.

Trost developed a Pd-catalyzed vinyl-substituted trimethylenemethane (TMM) asymmetric [3+2] cycloaddition with 1. $^{[17]}$ The transformation relied on the use of unprecedented bisdiamidophosphite ligand L5 and engendered tetrasubstituted cyclopentanes $\mathbf{2 3}$ in high yields with good regio-, diastereo- and enantioselectivities (Scheme 11). Due to the high functional tolerance at the $\beta$-position on the acyl-imidazole substrates, the products could be easily transformed into more elaborated compounds as illustrated with the synthesis of tricyclic adduct $\mathbf{2 4}$

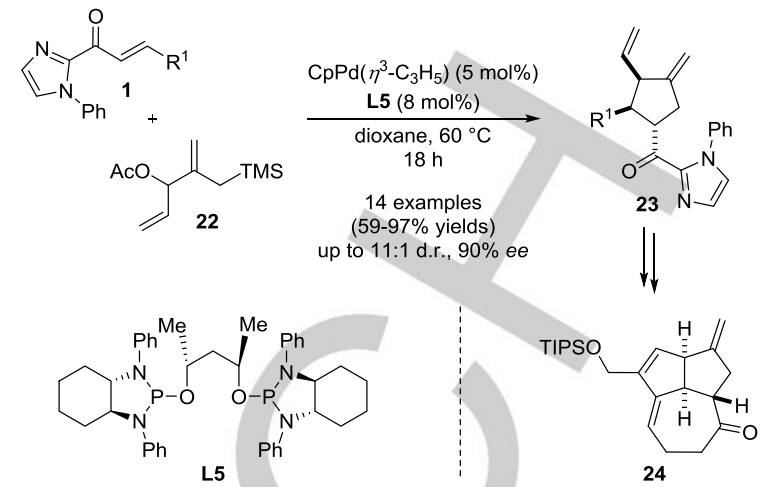

Scheme 11. [3+2] Cycloaddition of 1 with trimethylenemethane.

\subsection{2. $[4+2]$}

Liskamp and co-workers have proposed an alternative catalytic system based on the combination of bio-inspired triazacyclophane (TAC)-based ligands and $\mathrm{Cu}(\mathrm{II})$-salts. ${ }^{[8]}$ Even though these ligands could mimic the structure of the trishistidine triad metal-binding site found in metalloenzymes, low enantioselectivity ( $51 \%$ ee for the endo-product) was obtained. Higher selectivities are obtained with bio-hybrid catalysts in these reactions (see section 5).

\section{3. $\alpha$-Functionalization through acyl-imidazole enolates}

Enolate derivatives have been found to be versatile substrates for the $\alpha$-functionalization of acyl-imidazoles. $\alpha$-Alkylation of acyl-imidazole enolates was described by Trost and co-workers in $2010^{[18]}$ using the catalytic Asymmetric Allylic Alkylation (AAA) of a wide range of 2-acyl-imidazole enol carbonate derivatives 25 (Scheme 12). Thanks to this method, compounds 26 have been obtained in good yields and good enantioselectivities. This methodology was successfully applied to the enantioselective total synthesis of cetiedil 27.

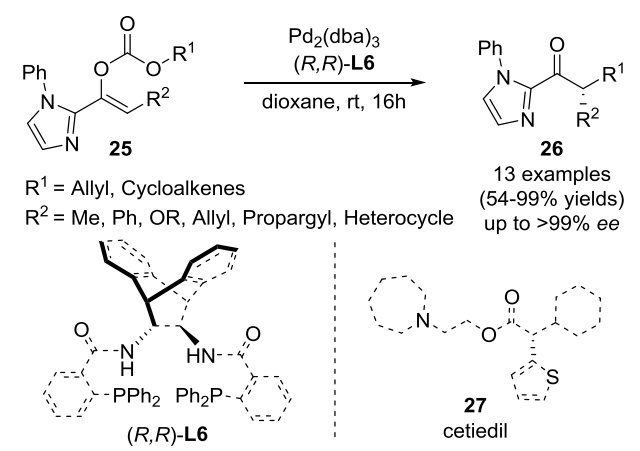

Scheme 12. AAA of 2-acyl-imidazoles 25 described by Trost and co-workers.

Following this pioneering work, the nickel-catalyzed enantioselective Michael addition on nitroalkene derivatives was investigated. The $\mathrm{N}, \mathrm{O}$-chelation of the chiral metal complex on the acyl-imidazole moiety facilitated the soft enolization of this nucleophile to afford a chiral metal enolate intermediate which could achieve enantioselective addition to an electrophile 
(Scheme 13). For this process, nickel complexes bearing chiral bisoxazoline ligands (L7 and L8) have been used.

$$
\text { (hiral metal enolate }
$$

Scheme 13. Mechanism rational for the Michael addition of acyl-imidazoles to nitroalkenes.

The concept could be illustrated by Lam and co-workers in $2013^{[19]}$ in the addition of the $\mathrm{N}$-methyl-2-acetyl-imidazole 28 on several nitroalkenes 29 (Scheme 14). In this case, aromatic $\beta$ substituted nitroalkenes displayed higher enantioselectivities.<smiles></smiles>

29

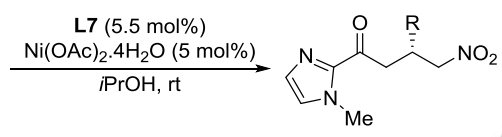

30
$\mathrm{R}=\mathrm{Ph}: \mathbf{8 5 \%}, 97 \%$ ee $\mathrm{R}=2-\mathrm{MeC}_{6} \mathrm{H}_{4}: 76 \%, 95 \%$ ee R = 1-Naphthyl: $82 \%, 97 \%$ ee $\mathrm{R}=\mathrm{Cy}: 54 \%, 67 \%$ ee

Scheme 14. Michael addition of 2-acetyl-1-methylimidazole to nitroalkenes.

The methodology could then be extended to the formation of quaternary centers (Scheme 15). ${ }^{[20,21]}$

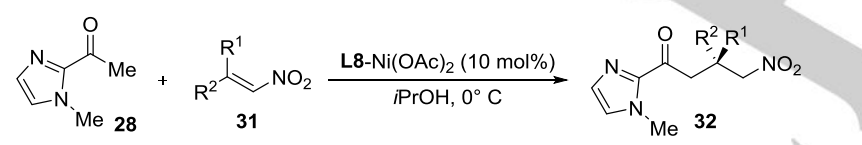

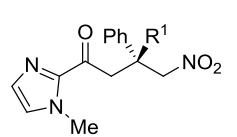

$\mathrm{R}^{1}=\mathrm{CF}_{3}: 81 \%, 96 \%$ ee $\mathrm{R}^{1}=\mathrm{CO}_{2}$ tBu: $92 \%,>99 \%$ ee
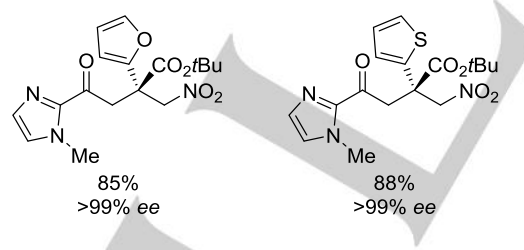

Scheme 15. Enantioselective formation of quaternary stereocenters via Michael addition of 2-acetyl-1-methylimidazole to nitroalkenes.

Wang and co-workers have described in 2017 the use of $\alpha$ substituted acyl-imidazoles 33 (if $R^{1} \neq \mathrm{H}$, Scheme 16). High anti diastereoselectivities, associated with excellent enantioselectivities, could be observed for a broad range of substrates. ${ }^{[22]}$ Interestingly, epimerization could be carried out under mild conditions to give the corresponding syn adducts 35 .

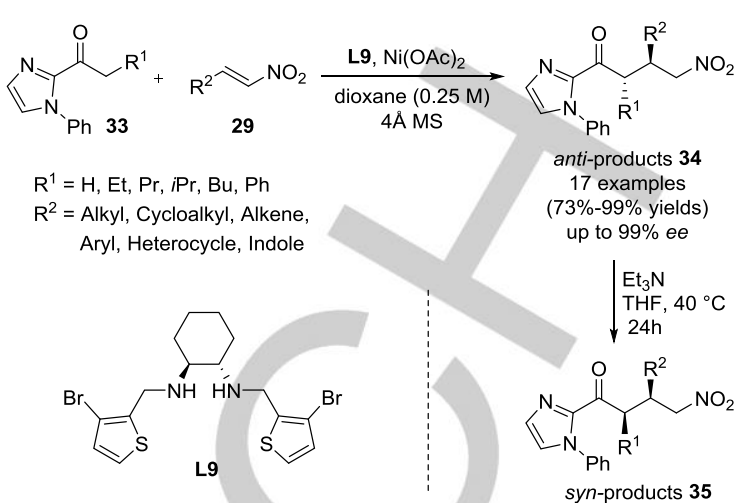

Scheme 16. Anti-selective Michael addition of acyl-imidazoles to nitroalkenes.

Recently, acyl-imidazole enolates were applied to the AAA reaction on nitroallylic acetate substrates 36 (Scheme 17). ${ }^{[23]}$ Using $\mathrm{Ni}(\mathrm{II})$-acetate source and the chiral diamine ligand L10 as optimized catalytic system, a wide scope of syn- $\alpha$-allylic adducts 37 was obtained.

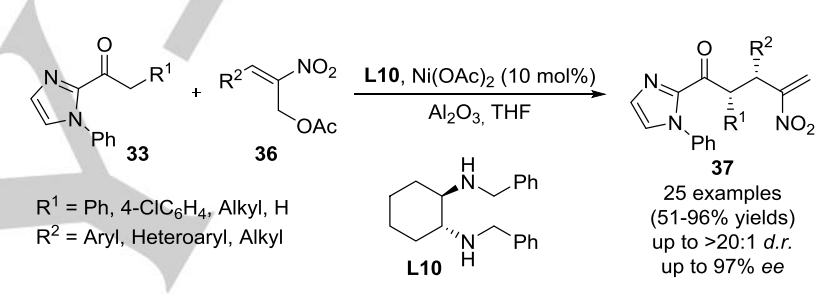

Scheme 17. AAA reactions between nitroallylic acetates and acyl-imidazoles.

\section{Metal-centered chirality catalysis}

\section{1. $\beta$-Functionalization through 1,4-additions (Friedel- Crafts; soft nucleophiles; organometallic reagents)}

In 2014, Meggers and co-workers introduced octahedral iridium (III) and rhodium (III) as a new class of chiral Lewis acid catalysts. $^{[24]}$ The general structure of these cationic complexes is relatively simple and contains only two cyclometallated benzoxazole or benzothiazole achiral ligands in addition to the two labile coordinated acetonitriles. These complexes that exclusively display octahedral metal centrochirality $(\Lambda$ or $\Delta)$ are configurationally stable (Scheme 18). In the past years, acylimidazoles have become the substrates of choice with such chiral catalysts allowing for high efficiency in a variety of asymmetric transformations. 


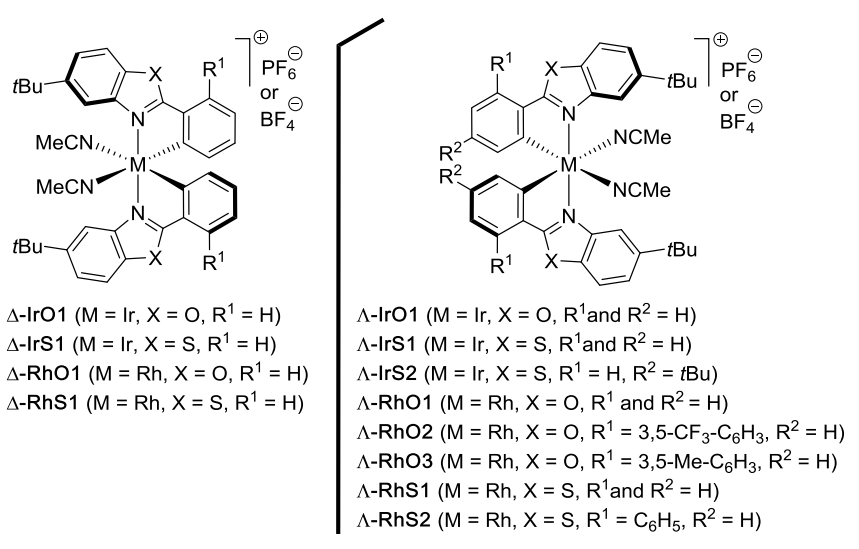

Scheme 18. Chiral-at-metal bis-cyclometallated $\operatorname{Ir}(\mathrm{III})$ and $\mathrm{Rh}(\mathrm{III})$ catalysts by Meggers and co-workers.

\subsubsection{Friedel-Crafts type additions}

The first example of successful asymmetric catalysis using this novel class of chiral transition metal catalysts was reported in the enantioselective $\mathrm{FC}$ reactions of $\mathbf{1}$ with electron-rich indoles 38. ${ }^{[25]}$ In 2014, Meggers and co-workers demonstrated that biscyclometallated octahedral iridium(III) complexes $\Lambda / \Delta$-IrO1 could induce high chirality transfer at room temperature with high functional group tolerance (Scheme 19).
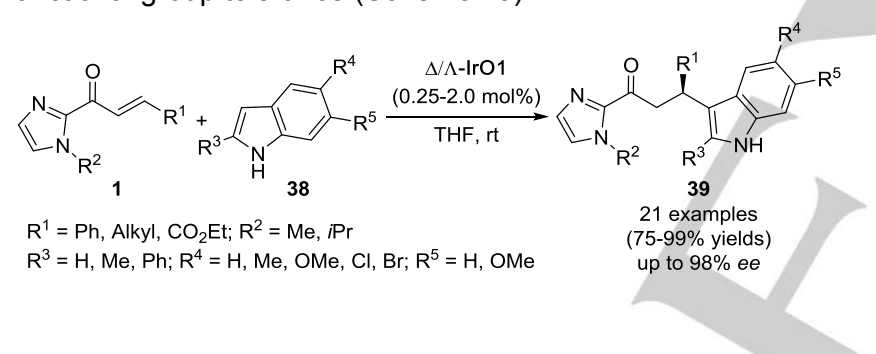

Scheme 19. FC reactions catalyzed by chiral-at-metal $\operatorname{Ir}(\mathrm{III})$ catalysts with indoles 38 and 1.

The same authors could further evidence the versatility of catalyst $\Lambda$-IrO1 and demonstrated that the 2phenylbenzothiazole-based complex $\Lambda$-IrS1 could provide higher asymmetric induction in the FC reaction with 3dimethylaminoanisole, 2-methoxyfuran and pyrrole to provide the desired products in high yields and high enantioselectivities (Scheme 20). ${ }^{[16]}$ Interestingly, crystal structure of the $\alpha, \beta$ unsaturated 2-acyl-imidazole substrate 1 a coordinated to the chiral iridium complex $\Lambda$-IrO1 could be obtained. It showed the shielding of the Si-face by one tert-butyl group that directed the nucleophilic attack to the Re-face. It is also important to note that the isostructural rhodium congener $\Lambda$-RhO1 was also described to display high selectivity in FC alkylation of indole (one example). ${ }^{\left[{ }^{[6]}\right.}$ In 2017, a polymer-supported chiral-at-metal $\operatorname{Ir}(I I I)$ Lewis acid was used in enantioselective FC alkylation and Diels-Alder (DA) reactions. ${ }^{[27]}$

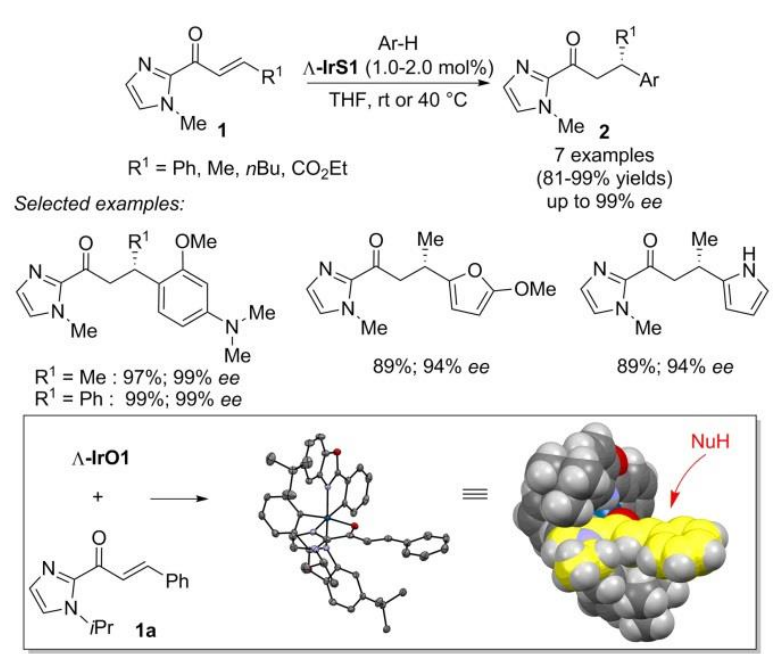

Scheme 20. FC reactions catalyzed by chiral-at-metal $\Lambda$-IrS1 catalysts. Adapted with permission from Ref. 16. Copyright 2015 John Wiley \& Sons.

The more challenging enantioselective C2-alkylation of 3 substituted indoles $\mathbf{4 0}$ with $\mathbf{1}$ was described by the same group in 2017. ${ }^{[28]}$ While complex $\Lambda$-IrO1 demonstrated poor catalytic activity in the C2-alkylation of 3-methylindole, the structurally modified catalyst $\Delta$-IrO-uracil exhibited improved activity and excellent enantioselectivity due to its bifunctional Lewis acid/hydrogen-bond network activity (Scheme 21). The authors proposed that the replacement of the tert-butyl groups on the catalyst by the hydrogen bond acceptor (i.e. $\mathrm{N}$-methyl uracil) increased the reaction rate by rendering the indole substrate more nucleophilic.

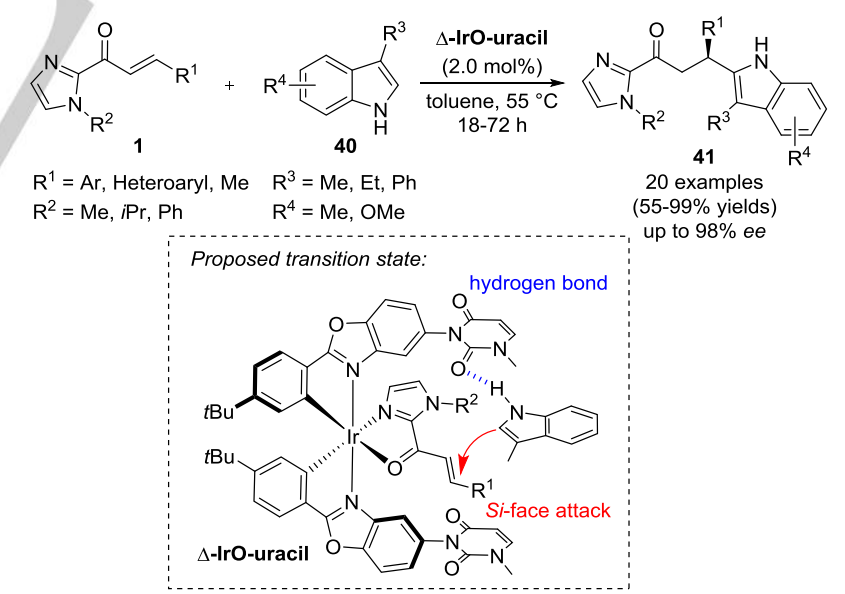

Scheme 21. FC reactions catalyzed by modified chiral-at-metal $\Delta$-IrO-uracil catalyst.

\subsubsection{Addition of soft nucleophiles}

In contrast to FC reactions, where $\operatorname{Ir}(\mathrm{III})$ complex gave better results (see above), octahedral $\Delta-\mathbf{R h O 1}^{[26]}$ and $\Lambda$-RhS1 ${ }^{[29]}$ complexes displayed better catalytic efficiency in Michael 
addition reactions with soft nucleophiles (Scheme 22). Moreover, the formation of all-carbon quaternary centers was also allowed with diastereoselectivities of up to $14: 1$. $^{[26]}$ Concerning the mechanism, it works like previously stated for these chiral-atmetal catalysts; bidentate fashion coordination with 2-acylimidazole substrate (chiral Lewis acid behavior) followed by the addition of the carbon nucleophile to the prochiral $\beta$-carbon. The $\mathrm{Rh}$ superiority on the conjugated addition of soft carbon nucleophiles is mainly due to the lability of acetonitrile ligands which could be easily replaced by acyl-imidazole substrates. Consequently, the $\mathrm{Rh}$ complexes afforded higher turnover frequencies and turnover numbers that limit non-catalyzed background reactions.

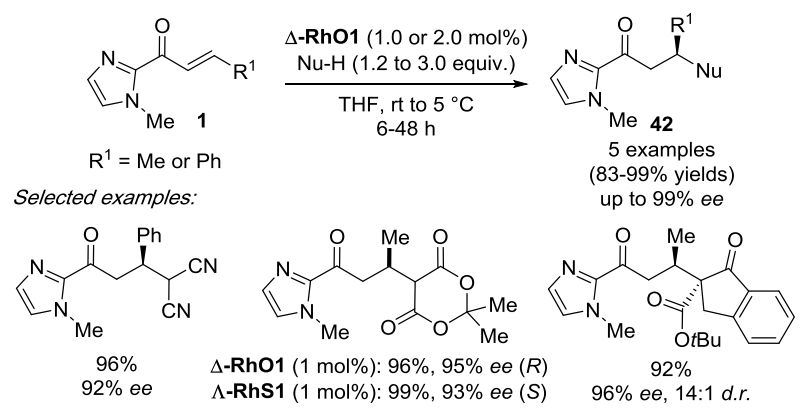

Scheme 22. Soft carbon nucleophiles on conjugate addition in the presence of Meggers' catalyst and $\mathbf{1}$.

Kang and co-workers recently described the use of $\Lambda$-RhO2 in the enantioselective conjugate addition of pyrazolones 43 to 1 (Scheme 23a). ${ }^{[30]} \mathrm{N}$-Methylimidazole unit was crucial to obtain high yields and enantioselectivities. In fact, when it was replaced by 2-pyridyl moiety (see 46) much lower ees were attained and in the presence of 1-pyrazole ring the transformation was very reluctant (traces of product $\mathbf{4 5}$ ) (Scheme 23b).

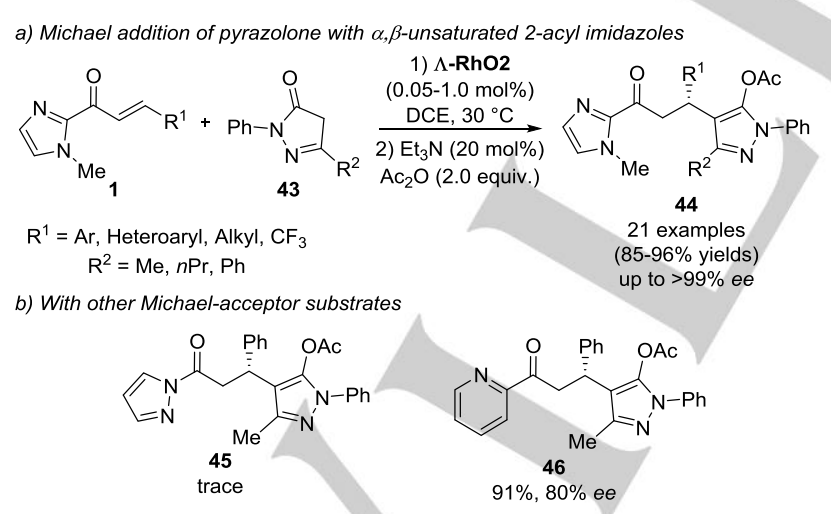

Scheme 23. Conjugate addition of pyrazolones to 1 .

Enantioselective sulfa-Michael addition to $\mathbf{1 b}$ bearing an ester function at the $\gamma$-position was described in $2015^{[31]}$ In this study, stable octahedral 3-aminopyrazolato $\operatorname{Ir}(\mathrm{III})$ complex ( $\Lambda$-IrO3), in which the two labile acetonitrile ligands were replaced by a pyridine/3-aminopyrazole moiety, was ideal for the asymmetric sulfa-Michael addition of aromatic thiols (down to $0.05 \mathrm{~mol} \%$ catalyst loading) (Scheme 24). The catalyst seems to act through both chiral Brønsted base/H-bonding activation. The plausible mechanism relies on a first proton transfer from the aromatic thiol to the catalyst followed by the thiolate addition to the Michael acceptor. Then, protonation releases the catalyst and ends the catalytic cycle. Again, 2-acyl-imidazoles (compared with different $\mathrm{N}$-acyl pyrazoles) were better substrates concerning enantioselectivity outcomes, probably due to its stronger hydrogen bond acceptor skills.

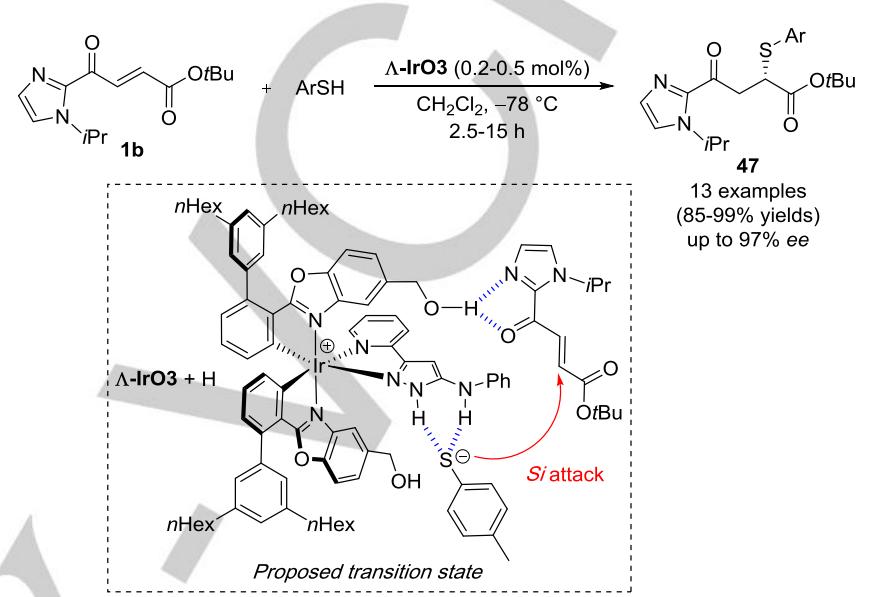

Scheme 24. Enantioselective sulfa-Michael addition to $\alpha, \beta$-unsaturated 2-acylimidazole 1b.

In 2017, Kang and co-workers proposed a protocol to achieve enantioselective aza-Michael addition through chemoselective conjugate addition of $\mathrm{N}$-protected hydroxylamines 48 to 1 (Scheme 25). ${ }^{[32]}$

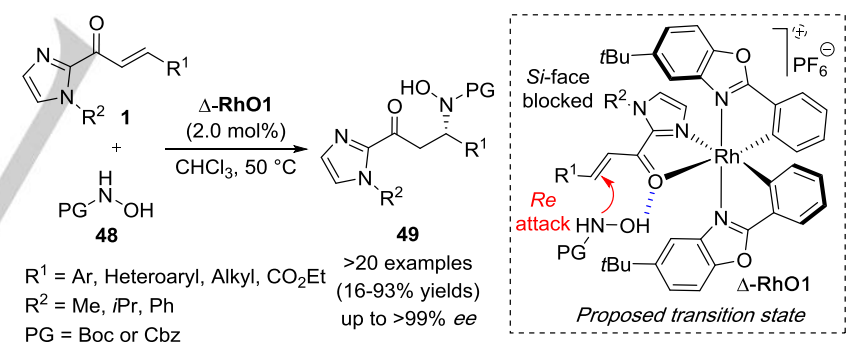

Scheme 25. Enantioselective aza-Michael addition of hydroxylamines to 1.

Along the same lines, and playing on the nature of the metal (Ir $v s \mathrm{Rh}$ ), decarboxylative addition of $\beta$-oxoacids ${ }^{[33]}$ and addition of nitroalkane derivatives have also been described. ${ }^{[34]}$

\subsubsection{Addition of 1,1'-diarylethenes}

The catalytic asymmetric addition of alkenyl nucleophiles to Michael acceptors represents an elegant way to build enantioenriched chiral centers adjacent to an alkenyl moiety. Studies disclosed in the literature are traditionally mainly based on vinyl organometallic reagents. ${ }^{[35]}$ Simple alkenes have been more scarcely investigated due to their poor reactivity and uncontrolled side reactions. Kang and co-workers recently reported a relevant enantioselective conjugate addition of 1,1'diarylethene $\mathbf{5 0}$ to various $\alpha, \beta$-unsaturated 2-acyl-imidazoles 1 catalyzed by a chiral-at-metal $\mathrm{Rh}(\mathrm{III})$ complex ( $\Lambda$-RhO2) 
(Scheme 26). ${ }^{[36]}$ The corresponding 1,4-adducts 51 were isolated in good yields and selectivities. It is noteworthy that a gram-scale reaction involving a catalyst loading as low as 0.05 mol\% was performed with a similar efficiency.

$$
\begin{aligned}
& \mathrm{R}^{1}=\mathrm{Alkyl} \text {, Aryl, Heteroaryl, } \mathrm{CO}_{2} \mathrm{Et} \\
& \mathrm{R}^{2}=\text { Me or } \mathrm{Pr}
\end{aligned}
$$

Scheme 26. Asymmetric conjugate addition of 1,1'-diarylethene to 1.

\subsubsection{Radical-based $\beta$-functionalization}

Merging bis-cyclometallated chiral $\mathrm{Rh}$ (III) complexes and $\alpha, \beta$ unsaturated acyl-imidazoles 1 under photoredox conditions gave a straightforward alternative route for highly enantioselective $\beta$ functionalization of such substrates. Alkyl radicals generated from organotrifluoroborates, ${ }^{[37]}$ nitrogen-centered radicals obtained through proton-coupled electron transfer (PCET), ${ }^{[3]}$ and $\alpha$-amino radicals supplied from tertiary amine derivatives ${ }^{[39]}$ allowed the formation of $\mathrm{C}-\mathrm{C}$ and $\mathrm{C}-\mathrm{N}$ bonds at the $\beta$-position of 1 in an impressive enantiocontrol. Additionally, remote, unactivated $\delta-\mathrm{C}\left(\mathrm{sp}^{3}\right)-\mathrm{H}$ bonds of $\mathrm{N}$-alkyl amides were also prone to radical formation and reaction under $\mathrm{Rh}(\mathrm{III})$-photoredox catalysis (Scheme 27). ${ }^{[40]}$

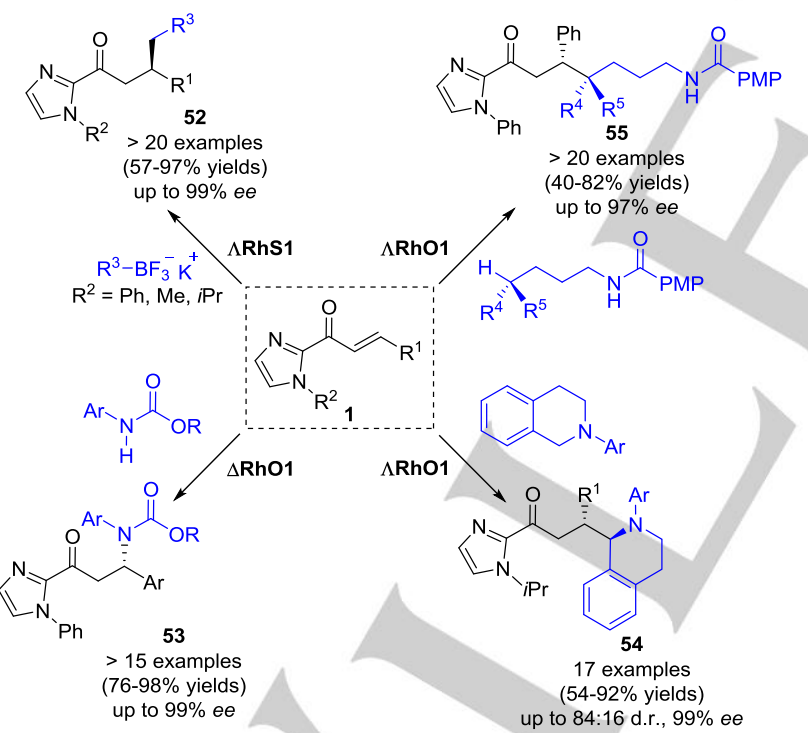

Scheme 27. $\beta$-Functionalization of 1 via photoredox with bis-cyclometallated $\mathrm{Rh}(\mathrm{III})$ catalysts.

Thanks to the ability of substrates $\mathbf{1}$ to efficiently coordinate to the catalysts through a bidentate manner, the combination of asymmetric catalysis and photoredox catalysis allowed this unique reactivity. In general, the catalytic cycle starts with the formation of $\mathrm{N}, \mathrm{O}-\mathrm{Rh}$ coordinated 2-acyl-imidazole substrate (intermediate I) (Scheme 28). Then, depending of the nature of the radical partner $\left(R^{\circ}\right)$, the intermediate $I$ can undergo either radical addition reaction to form intermediate Ila (mechanism $A$ ) or reduction to the rhodium enolate radical intermediate Ilb which recombine to generate intermediate III (mechanism B). After protonation (III $\rightarrow \mathrm{IV}$ ), product release and coordination of a new substrate $(I V \rightarrow I)$, a new cycle can be initiated.

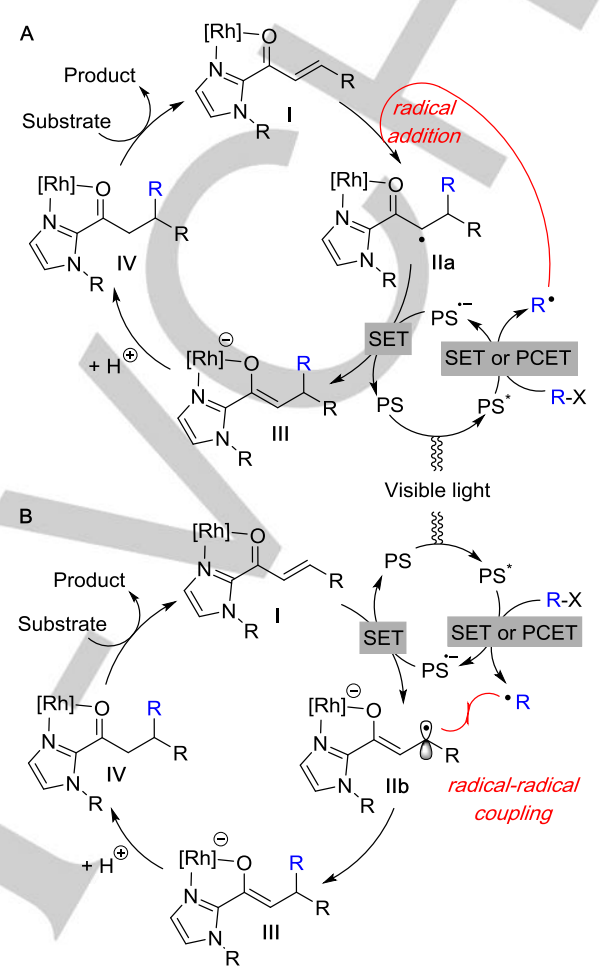

Scheme 28. Proposed mechanisms for radical-based enantioselective $\beta$ functionalization of 1 .

Very recently, the concept could be extended to the use of Hantzsch esters 56 as alkyl radical reservoirs (Scheme 29). ${ }^{[41]}$ The authors assumed that both mechanisms A and B could operate simultaneously.

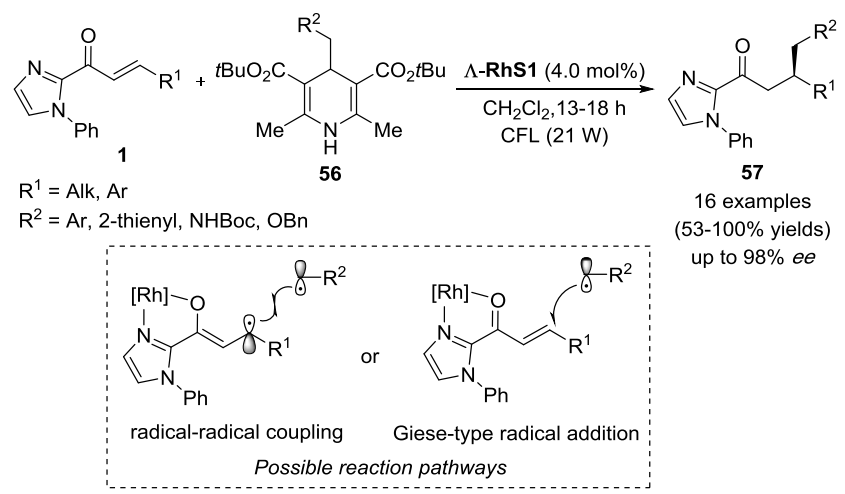

Scheme 29. Hantzsch esters on photoredox $\beta$-alkylation of 1. CFL = Compact Fluorescent Lamp.

\subsection{Cycloadditions}

3.2.1. [2+1] 
Kang and co-workers have employed chiral Rh(III) complex to catalyze asymmetric Michael-initiated ring-closure (MIRC) reaction between 1 and 2-bromomalonates 58 (Scheme 30). ${ }^{[42]}$ The polyfunctionalized cyclopropane products 59 were isolated in high yields, diastereo- and enantioselectivities. The illustrated transformation displayed good substrate tolerances concerning both 2-acyl-imidazole and bromomalonate substrates.

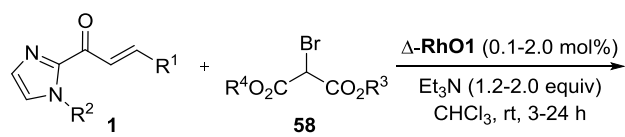

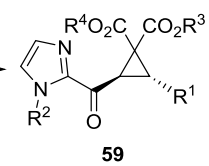

$\mathrm{R}^{1}=$ Aryl, Heteroaryl, $\mathrm{C}_{7} \mathrm{H}_{13}$

$\mathrm{R}^{2}=\mathrm{Me}$ or $\mathrm{Ph}$

$\mathrm{R}^{3} / \mathrm{R}^{4}=\mathrm{Et}, \mathrm{IPr}, \mathrm{Bn}, t \mathrm{Bu}$

Scheme 30. Cyclopropanes synthesis via [2+1] cycloadditions with $\mathbf{1}$.

\subsection{2. $[2+2]$}

Following a seminal publication by Yoon, ${ }^{[43]}$ Meggers developed an intermolecular photocatalytic [2+2] cycloaddition reaction enabling the formation of cyclobutanes 61 through reaction of $\alpha, \beta$-unsaturated 2-phenyl imidazoles and 2,3-dimethyl-1,3butadiene 60 (Scheme 31). ${ }^{[4]}$ Thanks to the ability of acylimidazole to form a chiral Rh/substrate complex which acted as a 'light harvesting antenna' and consequently suppressed racemic non catalyzed background reaction, high levels of selectivities were obtained.

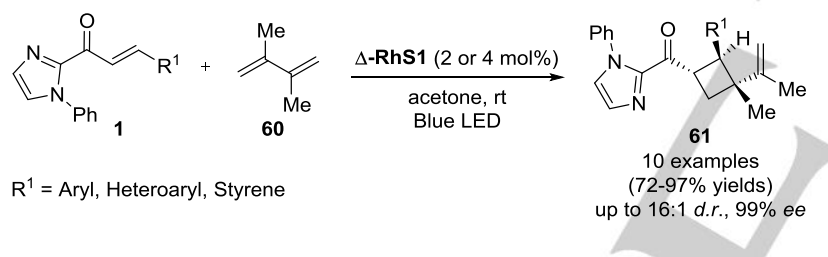

Scheme 31. Cyclobutanes synthesis through [2+2] cycloadditions with 1

\subsection{2. $[4+2]$}

$\alpha, \beta$-Unsaturated 2-acyl-imidazoles 1 are substrates of choice for performing [4+2] cycloadditions acting as both practical and alternative class of dienophiles. They exhibited excellent reactivity towards Diels-Alder (DA) reaction in the presence of metal-transition/ligands catalytic system or several biohybrid catalytic systems. In the field of chiral transition-metal catalysis, bis-cyclometallated chiral $\Lambda$-IrO1 complex displayed excellent diastereo- and enantioselectivities in DA and hetero-Diels-Alder (HDA) reactions (Scheme $32 a) .{ }^{[16]}$ Switching to $\Lambda$-RhO1 complex, the synthesis of several hydrocarbazoles 64 through DA reaction between $N$-Boc-protected 3-vinylindole 63 and $\beta$ carboxylic ester-substituted $\alpha, \beta$-unsaturated acyl-imidazoles 1d was reported (Scheme $32 \mathrm{~b}$ ). ${ }^{[45]}$ The compounds were isolated in high regio-, diastereo- and enantioselectivities. In both cases, the $\operatorname{Ir}(\mathrm{III})$ - and $\mathrm{Rh}(\mathrm{III})$-catalysts act as chiral Lewis acids to activate the acyl-imidazole through bidentate coordination with the carbonyl and nitrogen binding sites.

(a)

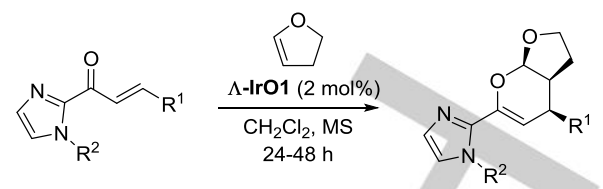

$$
\text { 1c: } R^{1}, R^{2}=M e
$$

1a: $\mathrm{R}^{1}=\mathrm{Ph}, \mathrm{R}^{2}=i \mathrm{Pr}$

(b)

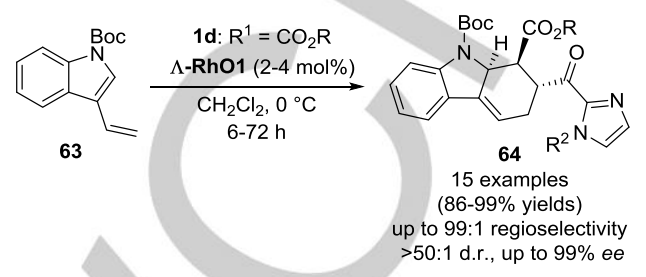

Scheme 32. DA and HDA reactions with $\alpha, \beta$-unsaturated acyl-imidazoles 1.

\section{3. $\alpha$-Functionalization of acyl-imidazole derivatives}

\subsubsection{Asymmetric photoredox catalysis ( $\alpha$-radicals)}

Prior to the use of $\alpha, \beta$-unsaturated 2-acyl-imidazoles 1, $\alpha$ alkylation processes have been reported by Meggers and coworkers on saturated 2-acyl-imidazoles. The enantioselective $\alpha$ alkylation of $\mathbf{3 3}$ with electron deficient benzyl bromides and phenacyl bromide derivatives 65 was described in the presence of $\Lambda$-IrS1 complex (Scheme 33). ${ }^{[46]}$ The addition of a weak base (i.e. $\mathrm{Na}_{2} \mathrm{HPO}_{4}$ ) to facilitate the enolate chemistry, together with the optimization of concentration and temperature parameters, allowed better conversions at a reduced reaction time.
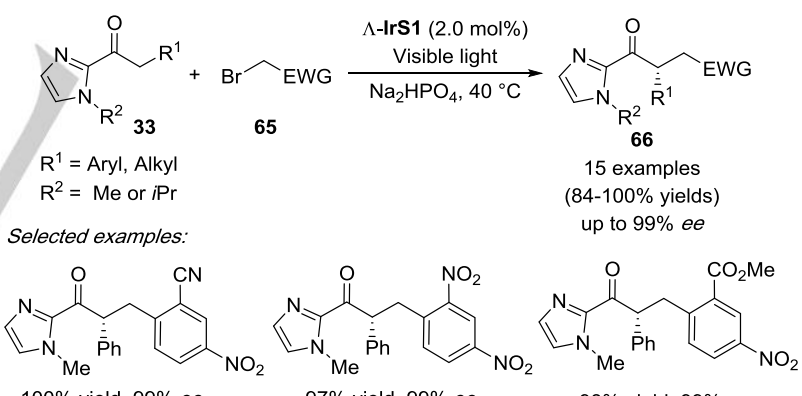
$100 \%$ yield, $99 \%$ ee $\quad 97 \%$ yield, $99 \%$ ee $\quad 98 \%$ yield, $99 \%$ ee

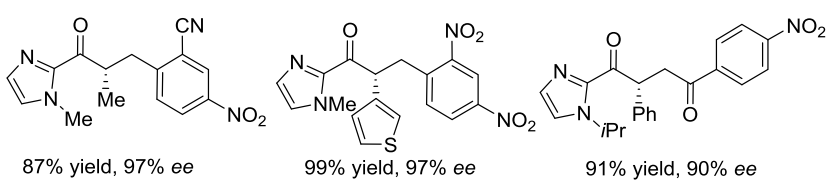

Scheme 33. $\alpha$-Alkylation of saturated 2-acyl-imidazoles 33 with benzyl and phenacyl bromide derivatives.

As previously described for unsaturated substrates (see 2.6 Radical additions), the key intermediates were the nucleophilic Ir(III) enolate complex (intermediate II, obtained by $\alpha$ deprotonation) and the electrophilic radical derived from the photoredox cycle after bromine discharge (Scheme 34). By merging both cycles (the asymmetric and the photoredox ones) the key intermediate III was formed. Then, through a SET 
oxidation, III gave intermediate IV that ended the catalytic cycle via final exchange with unreacted substrate.

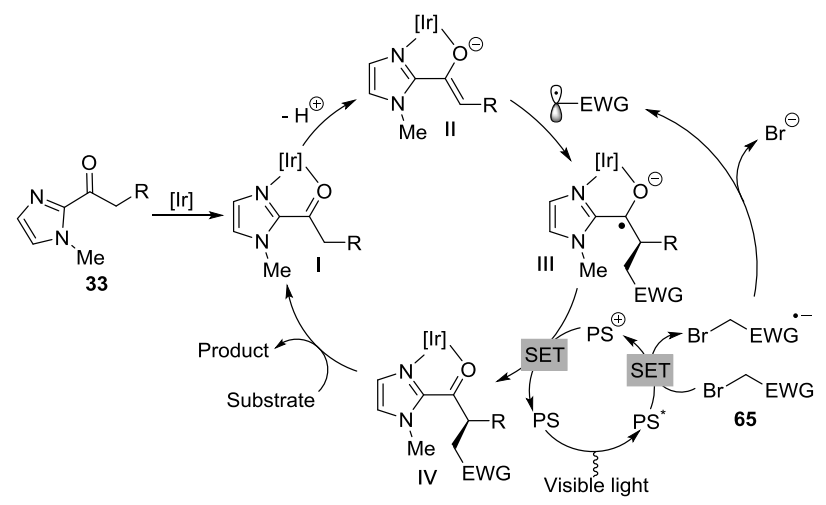

Scheme 34. Proposed mechanism for the $\alpha$-alkylation of $\mathbf{3 3}$ with derivatives 65.

The enantioselective $\alpha$-trichloromethylation ${ }^{[47]}$ (Scheme 35a) and $\alpha$-perfluoroalkylation ${ }^{[48]} \quad$ (Scheme $35 \mathrm{~b}$ ) of $\mathbf{3 3}$ using bromotrichloromethane or perfluoroalkane iodides as reagents were next described by the same group. (a)

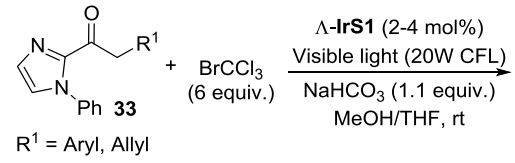

(b)

$$
\begin{aligned}
& \mathrm{Ar}=2-\mathrm{MePh} \\
& \mathrm{R}^{1}=\mathrm{Aryl}_{\mathrm{Ar}} \text { Alkyl } \\
& \mathrm{R}_{\mathrm{f}} \mathrm{l}=\mathrm{C}_{n} \mathrm{~F}_{2 n+1} \mathrm{l} \text { or } \mathrm{C}_{6} \mathrm{~F}_{5} \mathrm{CF}_{2} \mathrm{I}
\end{aligned}
$$

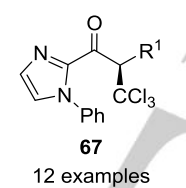
$(64-96 \%$ yields) up to $>99.9 \% e e$

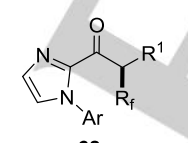

14 examples $(43-93 \%$ yields up to $>99.5 \%$ ee
Scheme 35. $\alpha$-Trichloromethylation and $\alpha$-perfluoroalkylation of 33.

After proving that chiral octahedral Ir(III) complexes were able to carry out $\alpha$-functionalization under reductive activation, Meggers and co-workers investigated enantioselective $\alpha$-alkylations under oxidative conditions (Scheme 36 ). ${ }^{[49]}$ From the enantiopure $\Lambda$ IrO1 complex exposed to air and an $\alpha$-silylamine 69 , a radical cation is produced which undergoes a rapid $\alpha$-deprotonation to afford an $\alpha$-aminoradical that after air oxidation can give the intermediate iminium III. This iminium can react with the nucleophilic iridium enolate II (Scheme 36), to get the expected product after exchange with unreacted substrate. Thus, in this oxidative process, contrary to the mechanism described above, the photoredox catalysis plays only a role in the generation of the electrophilic iminium III. Through this process, chiral $\beta$-amino functionalized acyl-imidazoles $\mathbf{7 0}$ were obtained in good yields and enantioselectivities.

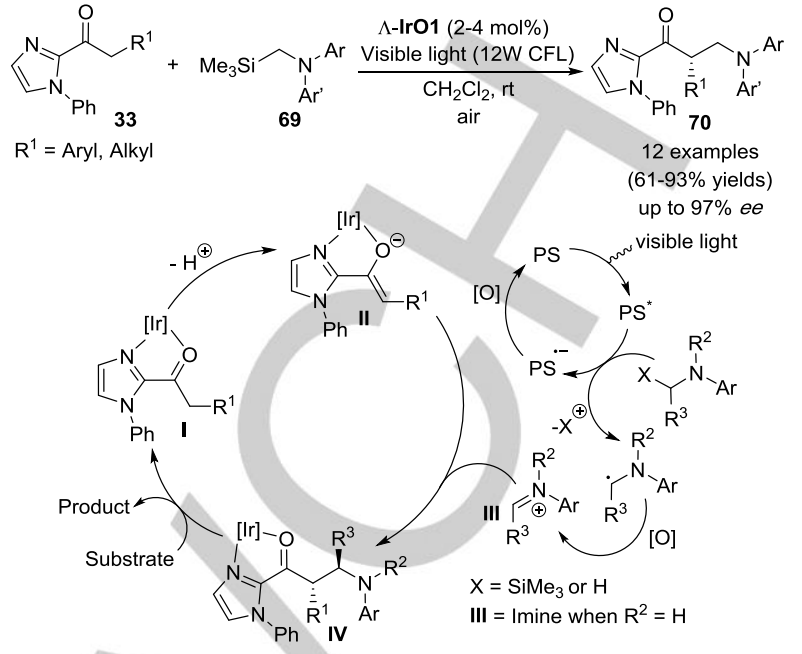

Scheme 36. $\alpha$-Alkylation under oxidative conditions of saturated 2-acylimidazoles with $\alpha$-silylamines and proposed mechanism.

Moreover, by using blue LED, Meggers, Gong and co-workers have reported that $\Lambda$-RhO1 could be used as photosentizer for the $\mathrm{C}-\mathrm{H}$ activation of alkyl amine substrates to generate the key intermediate III (Scheme 36). ${ }^{[50]}$ Then, III could react with the rhodium-enolate complex II following the same mechanism described above (Scheme 36) to make the aerobic asymmetric $\mathrm{Csp}^{3}-\mathrm{H}$ cross coupling reaction (Scheme 37 ). Concerning the substrate scope, despite moderate yields, good enantioselectivities with high substituent tolerances for the aromatic groups on the amine or the acyl-imidazole were observed. Thus, in this work they proved that chiral rhodium complexes could serve both as catalyst for the enantioselective enolate chemistry and as visible-light-activated photoredox catalyst.

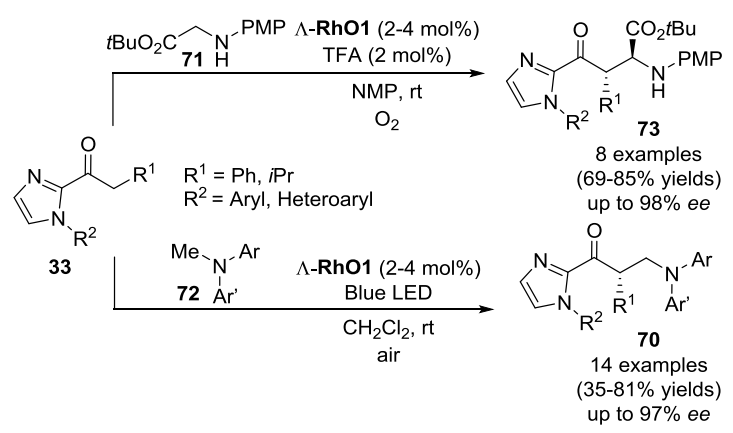

Scheme 37. Asymmetric $\mathrm{Csp}^{3}-\mathrm{H}$ cross coupling reactions in the presence of $\mathrm{Rh}$ (III) catalysts.

The enantioselective alkylation and amination of $\mathbf{3 3}$ with diazo 74 or azide 75 compounds have been next developed. In this work, benzothiazole analogues $\Lambda / \Delta-\mathbf{R h S} \mathbf{1}^{[29]}$ displayed better efficiency (Scheme 38). ${ }^{[51]}$ The proposed mechanism involves cooperation between the photoredox cycle catalyzed by the ruthenium complex and the asymmetric catalytic cycle based on the chiral rhodium complex. While, two different transition-metal 
based catalysts are necessary in this case, strong similarity can be found with the previously described mechanism in scheme 34 In this paper, a wide substrate scope is allowed showing the good functional groups tolerance of these reactions. The procedure is also compatible with natural products scaffolds such as cholesterol, menthol, L-(-)-borneol or geraniol fragments.
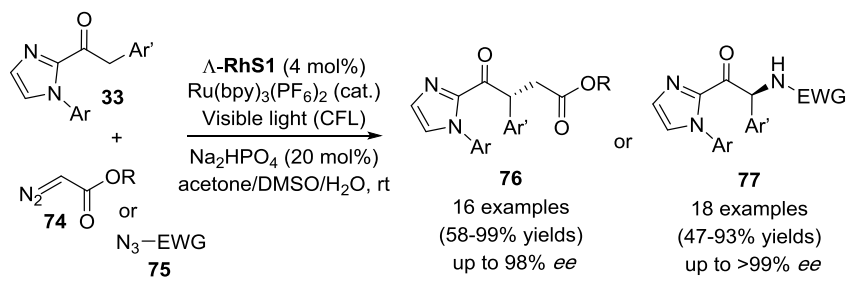

Scheme 38. Asymmetric $\alpha$-alkylation and $\alpha$-amination of 2-acyl-imidazoles 33 .

In the reaction between 2-acyl-imidazoles and 2,4dinitrophenylsulfonyloxy-carbamates, no $\mathrm{C}-\mathrm{N}$ bond formation has been observed with iridium catalyst whereas the rhodium analogue $\Delta$-RhO1 allowed the formation of the desired products with excellent results (yields up to $99 \%$, enantioselectivity up to $98 \%$ ). Mechanistic studies highlighted that this striking difference is mainly due to kinetic effects. Indeed, because of the high reactivity and short life time of the amidyl radical generated during the reaction, a high turnover frequency is required to ensure the catalytic reaction. Thus, despite their inferior ability to light-activate substrates, the rhodium complexes have faster ligand exchange kinetics than the iridium systems which better match with the high reactivity of the nitrogen-centered radical intermediates. ${ }^{[52]}$

The methodology could be next extended to the $\mathrm{C}\left(\mathrm{sp}^{3}\right)-\mathrm{H} \beta-$ functionalization with 1,2-dicarbonyl compounds 78 (Scheme 39). ${ }^{[53]}$ A wide range of chiral $\gamma$-hydroxy acyl-imidazole 79 was obtained in good yields and good diastereo- and enantioselectivities.

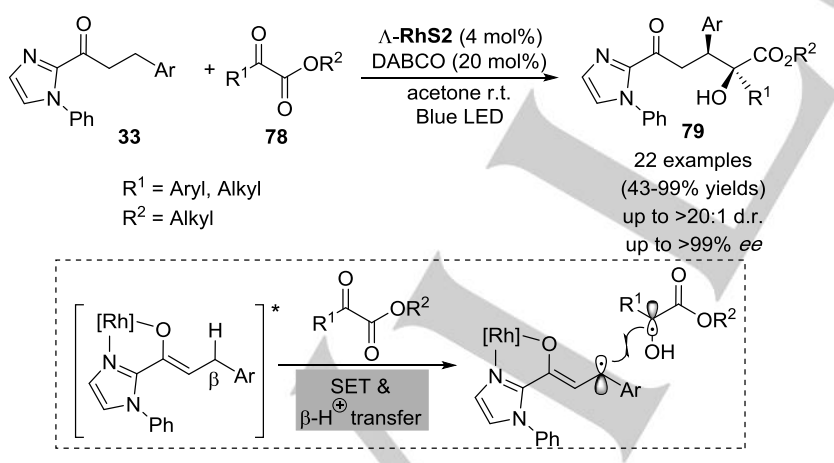

Scheme 39. Enantioselective $\beta-\mathrm{C}\left(\mathrm{sp}^{3}\right)-\mathrm{H}$ functionalization of $\mathbf{3 3}$.

Recently, the sequential photoredox chemistry and Asymmetric Transfer Hydrogenation (ATH) between the saturated 2-acylimidazole $\mathbf{3 3 a}$ and the $\alpha$-bromo ketone $\mathbf{8 0}$ in presence of $\Lambda$-IrS1 catalyst was reported (Scheme 40). ${ }^{[54]}$ First, the formation of the intermediate $\mathbf{8 1}$ takes place, as previously described in scheme 34 via the reaction of the Ir-enolate complex (obtained after $\alpha$ deprotonation) with the phenacyl electrophilic radical. Then, after solvent exchange and the addition of both the ammonium formate as hydride source and the 3,5-dimethylpyrazole (dmp) ligand, the ketone was reduced through ATH reaction.

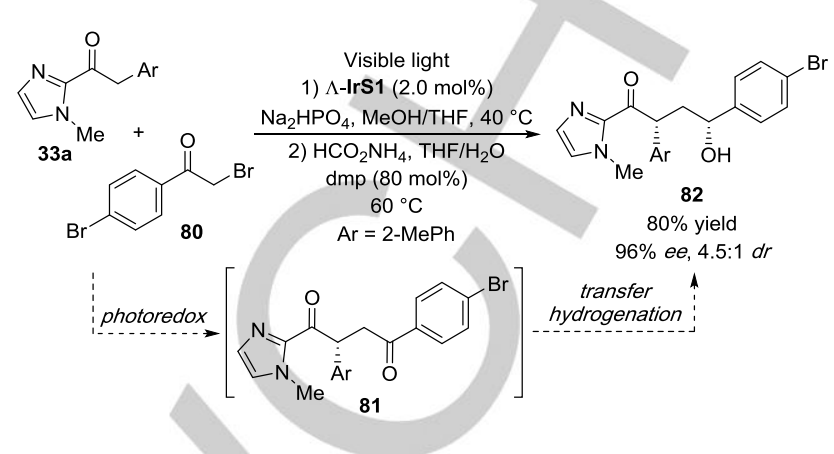

Scheme 40. $\alpha$-Functionalization of 33a via sequential photoredox and ATH reactions.

\subsubsection{Asymmetric Lewis acid catalysis}

If chiral octahedral $\mathrm{Rh}(\mathrm{III})$ or $\mathrm{Ir}(\mathrm{III})$ are efficient for the $\alpha$ functionalization of saturated acyl-imidazole through asymmetric photoredox processes, they can also be used as Lewis acid catalysts in acyl-imidazole enolate chemistry. In 2015, the $\alpha$ amination of substrates 33 using either $\Lambda$-IrO1 or $\Lambda$-RhO1 as Lewis acid catalyst (Scheme 41) was reported. ${ }^{[26]}$ In this transformation, $\Lambda$-RhO1-based complex has been the most efficient catalyst affording enantioselectivities up to $97 \%$ ee.

$$
\begin{gathered}
\begin{array}{c}
83 \\
(2 \text { equiv. })
\end{array} \\
\mathrm{R}^{1}=\text { Aryl, 3-thienyl, Me }
\end{gathered}
$$

Scheme 41. Enantioselective $\alpha$-amination of 2-acyl-imidazoles 33.

In 2016, Xu and co-workers have developed the $\alpha$-fluorination of 33 using $\Delta$-IrS1 as catalyst and selectfluor as fluorine source (Scheme 42) ${ }^{[55]}$ After optimization, a wide range of $\alpha$-fluorated 2-acyl-imidazole derivatives $\mathbf{8 5}$ has been obtained in good yields and good enantioselectivities.

$$
\begin{aligned}
& \begin{array}{c}
\text { Selectfluor }(1.2 \text { equiv. }) \\
\text { MeOH, } 20^{\circ} \mathrm{C}
\end{array} \\
& \mathrm{R}^{1}=\mathrm{Aryl}, 3-\mathrm{Thienyl,} \mathrm{Alkyl}
\end{aligned}
$$

Scheme 42. Enantioselective $\alpha$-fluorination of 2-acyl-imidazoles 33 .

Moreover, the $\alpha$-functionalization of saturated 2-acyl-imidazoles 33 with oxindole derivatives 86 allowed the synthesis of 3,3disubstituted oxindoles 87 in excellent selectivities (Scheme 43). ${ }^{[56]}$ 


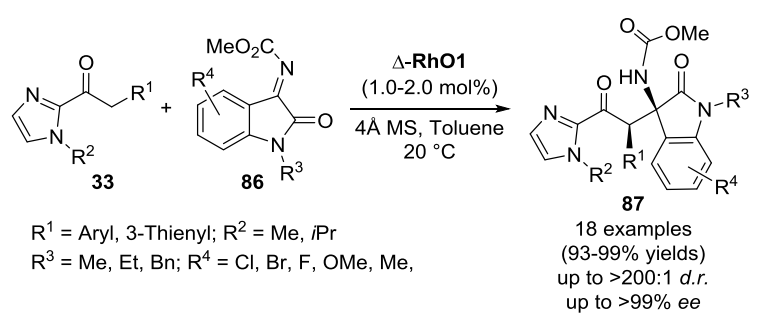

Scheme 43. Enantioselective synthesis of 3,3-disubstituted oxindoles.

One-pot three component Mannich reactions ${ }^{[57]}$ and the use of triazinanes $\mathbf{8 8}$ as aryl imine sources have next been described (Scheme 44). ${ }^{[58]}$

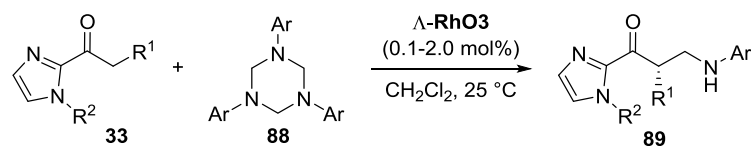

$$
\begin{aligned}
& \mathrm{R}^{1}=\text { Aryl, 3-Thienyl, Alkyl } 27 \text { examples } \\
& \begin{array}{ll}
\mathrm{R}^{2}=2-\mathrm{MePh} & (81-99 \% \text { yields }) \\
& \text { up to }>99 \% \text { ee }
\end{array}
\end{aligned}
$$

Scheme 44. Enantioselective Mannich reaction with $\mathbf{3 3}$ and triazinanes $\mathbf{8 8}$

Recently, Kang and co-workers have reported the enantioselective conjugate addition of saturated 2-acylimidazoles on nitroalkenes catalyzed by chiral Lewis acid complex $\Lambda$-RhO2 (Scheme 45). ${ }^{[59]}$

$$
\begin{aligned}
& \mathrm{R}^{1}=\mathrm{Aryl}, \mathrm{Heteroaryl,} \text { Alkyl, } \mathrm{CO}_{2} \mathrm{Et} \\
& \mathrm{R}^{2}=\mathrm{Me}, \mathrm{Pr}
\end{aligned}
$$

Scheme 45. Conjugate addition through Lewis acid catalysis of 33 on nitroalkenes.

\section{Organocatalysis}

In the field of the $\alpha$-functionalization of acyl-imidazole derivatives, Andrus and co-workers have used Phase-Transfer-Catalysis (PTC) with cinchonidinium catalysts to show that saturated 2acyl-imidazole $\mathbf{3 3 b}$ is a very suitable nucleophile to react with allyl and benzyl electrophiles (Scheme 46). ${ }^{[60]}$ The reaction rationale was relied on the $\alpha$-hydrogen of substrate $33 \mathbf{b}$ which is acidic enough to ensure good reactivity through an ion-pair mechanism at mild conditions $\left(-40^{\circ} \mathrm{C}\right)$ (see enol intermediate I). The observed $S$ stereochemistry for the products was explained through a transition state model (see TS-S) where the Z-enolate of the acyl-imidazole is located between both the quinoline and quinuclidine moieties of the catalyst. The oxygen of the enolate is ion-paired with the least encumbered face of the ammonium nitrogen. Thus, an extended $\pi$-system of enolate and imidazole ring is obtained which interacts with the quinoline part of the catalyst structure. Moreover, the 2-NPM protecting group (i.e. 2naphthylmethyl) is aligned with the aryl moiety bore by the ammonium nitrogen. Another point that was stressed by the authors was the facility to post-transform the imidazole moiety into other functionalities. Indeed, the PTC asymmetric acylimidazole alkylation methodology was further applied to the synthesis of kurasoin $B \mathbf{9 1}^{[61]}$ and to the formal synthesis of 12 (S)-hydroxy-eicosatetraenoic acid [12-(S)-HETE] 92. ${ }^{[62]}$

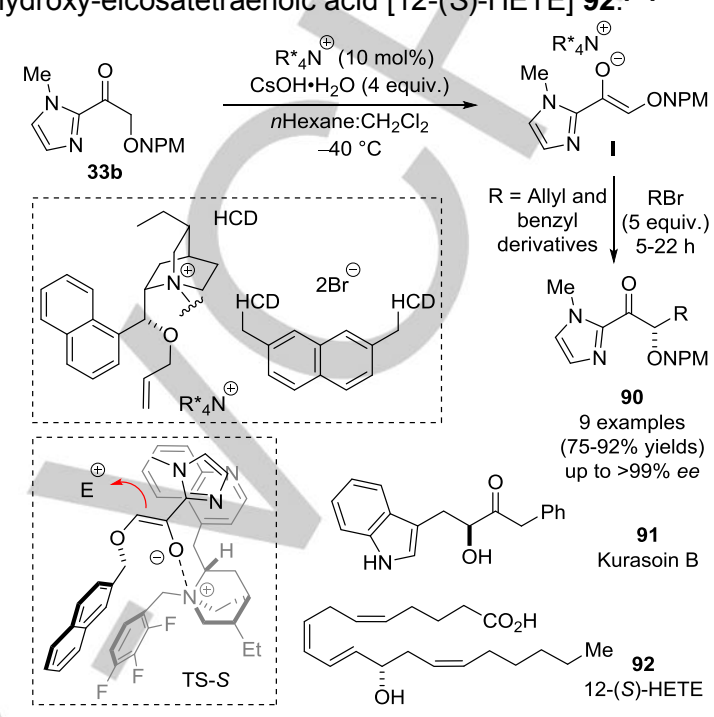

Scheme 46. $\alpha$-Alkylation of 2-naphthylmethyloxy acyl-imidazoles through PTC catalysis. NPM = 2-naphthylmethyl.

In 2010, the potential of quaternary ammonium catalysts and 2acyl-imidazole substrates was further extended to chemo- and enantioselective oxidative cycloetherification by Ishihara and coworkers (Scheme 47).
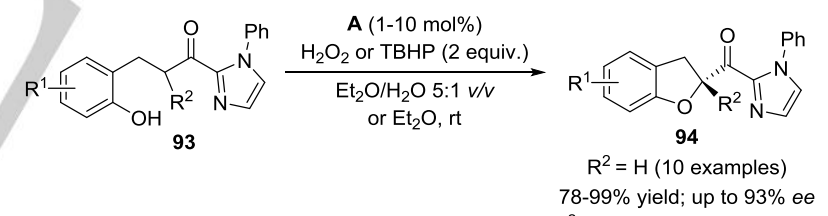
$78-99 \%$ yield; up to $93 \%$ ee
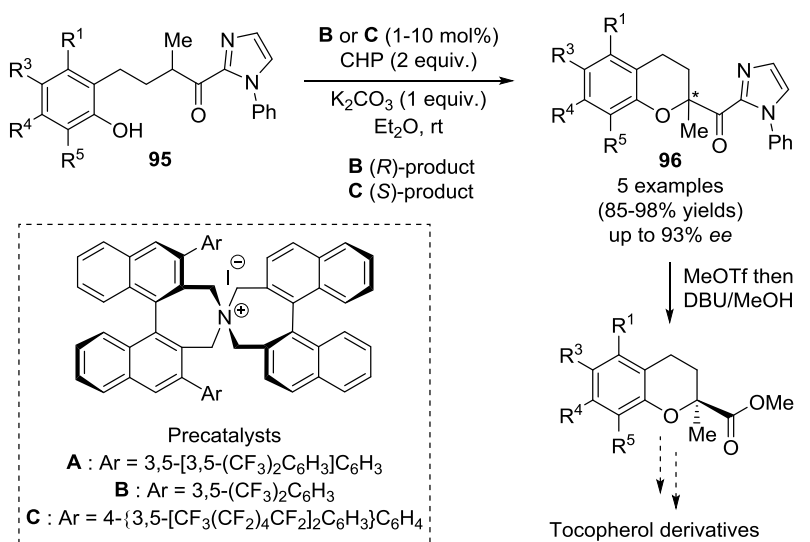

Scheme 47. Chemo- and enantioselective oxidative cycloetherification of 2acyl-imidazoles with chiral quaternary ammonium salts.

By combining in situ generated chiral quaternary ammonium (hypo)iodite salts with peroxides the enantioselective synthesis 
of five-membered (2-acyl 2,3-dihydrobenzofurans ${ }^{[63]}$ or 2-acyl

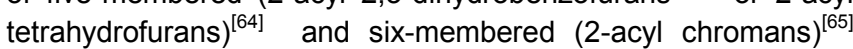
rings could be achieved. Interesting to note, the formation of quaternary stereocenters was also allowed. Finally, thanks to both the ability of acyl-imidazoles to induce excellent enantioselectivities and their easy post-functionalization, the formal asymmetric synthesis of tocopherols could be successfully achieved. ${ }^{[65]}$ It is interesting to mention that acylimidazoles were also prone to intermolecular $\alpha$-oxoacylation with carboxylic acids in the presence of (hypo)iodate catalysts even though not yet enantioselective. ${ }^{[66,67]}$

In 2015, the organocatalyzed enantioselective conjugate addition of an aryl trifluoroborate nucleophile to an 2-acylimidazole Michael acceptor was described (Scheme 48). ${ }^{[68]}$ It is worth to underline that ester and amide Michael acceptors failed to provide the corresponding 1,4-adducts whereas the remarkable reactivity of the 2-acyl-imidazole represents a synthetic alternative for their access.

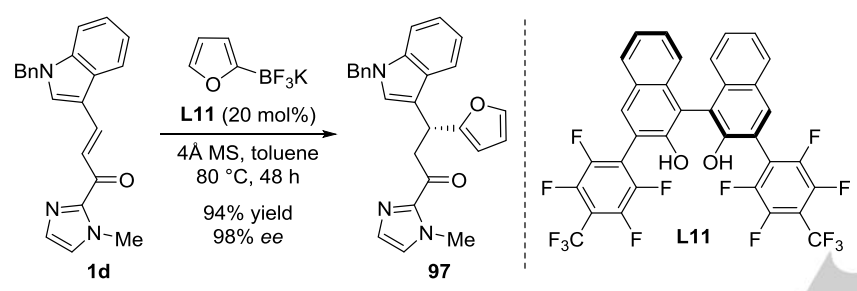

Scheme 48. Organocatalyzed enantioselective conjugate addition of aryl trifluoroborate to $\alpha, \beta$-unsaturated 2-acyl 1-methylimidazole.

In 2016, 2-acyl-imidazole acceptors were also used in a stepwise strategy for the atroposelective Hantzsch-type synthesis of 4-arylpyridines. ${ }^{[69]}$ The work combines organocatalyzed enantioselective Michael addition synthesis of 4-aryl-1,4-dihydropyridines (with bifunctional Takemoto's thiourea catalysis) followed by a central-to-axial chirality switch via an oxidative aromatization (with $\mathrm{MnO}_{2}$ ).

\section{Dual or cooperative catalysis}

In 2016, a merger of enamine and Lewis acid activation (i.e. dual catalytic system composed by chiral-at-metal $\mathrm{Rh}(\mathrm{III})$ - and an organo-catalyst) gave a synergistic system that successfully enabled the alkylation of aldehydes with $\alpha, \beta$-unsaturated 2-acylimidazoles 1 (Scheme 49). ${ }^{[70]}$ Isobutyraldehyde and symmetrical aldehydes 98 worked well on this Michael addition reaction (>15 examples, up to $99 \%$ ee). Moving to linear aliphatic aldehydes high yields albeit with low diastereoselectivities were observed. The use of Jørgensen-Hayashi catalyst was thus tried in combination with chiral-at-metal $\mathrm{Rh}$ (III) catalyst, however only a moderate improvement of the diastereomeric ratio (1.0:1.4 to 1.0:4.0) was obtained with a very high enantioselectivity for the major diastereomer $(98 \%$ ee $)$. This point supports the hypothesis that the chiral-at-metal catalyst was the only one responsible for the stereoselection.

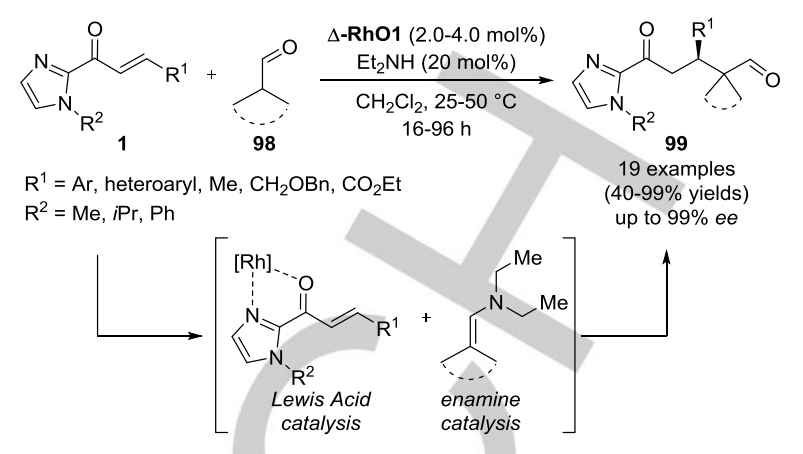

Scheme 49. Michael reactions of 1 with aldehydes 98 via dual catalysis.

A similar transformation using a $\Delta$-RhO-based precatalyst embedding both the metal-transition and the organocatalyst was also described. ${ }^{[71]}$ Accordingly, the L- $\beta$-phenylalanine (i.e. organocatalyst present in the coordination sphere of the $\mathrm{Rh}(\mathrm{III})$ precatalyst) was released during the initiation of the catalytic cycle through bidentate coordination of the Rh(III) with the 2acyl-imidazole substrate. Moreover, the conjugate addition of cyclic ketones to 1 was also devised affording a broad range of products 101 in high yields, high enantioselectivities and moderate to good diastereoselectivities (Scheme 50). ${ }^{[72]}$
作

$\mathrm{R}^{1}=$ Ar, Heteroaryl, Et, Me

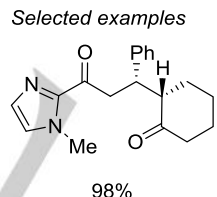

7:1 d.r.; $99 \%$ ee

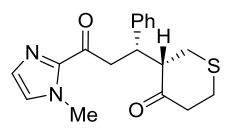

$92 \%$
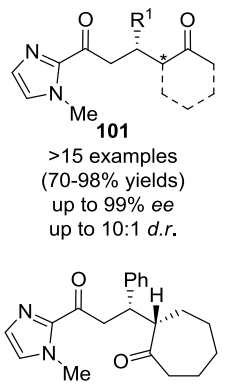

$70 \%$

2:1 d.r.; $59 \%$ ee
Scheme 50. Conjugate addition of cyclic ketones with 1 through dual metaltransition and organo-catalysis.

The concept of cooperative catalysis was used by $\mathrm{Hu}$ and coworkers during the enantioselective synthesis of $\gamma$ hydroxyketones 103 bearing a tetrasubstituted carbon stereocenter via multicomponent reactions (MCRs) (Scheme $51)^{[73]}$

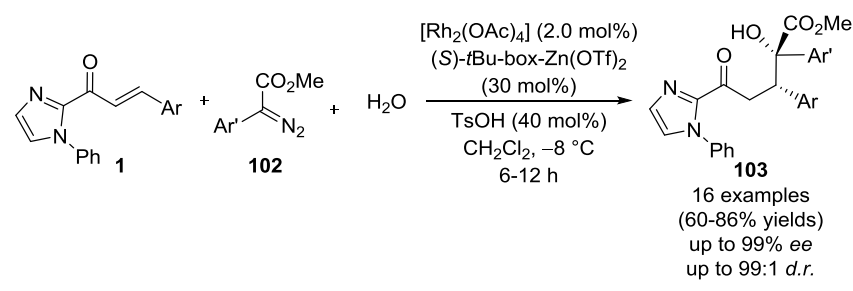

Scheme 51. Multicomponent reaction via cooperative catalysis towards the synthesis of tetrasubstituted $\gamma$-hydroxyketones. 


\section{Summary and Outlook}

While the use of acyl-imidazole in biohybrid catalytic transformations are described by Arseniyadis, Smietana and coworkers in the back-to back accompanying paper, ${ }^{[74]}$ we intend, through this minireview, to describe the potential of acylimidazole derivatives as valuable substrates for enantioselective transformations. Since the seminal publication in 2005 by Evans and co-workers on their use in enantioselective Friedel-Crafts reactions, such ester surrogates have attracted intensive interest among the synthetic chemists community. Indeed, most of the published papers (> 90\%) appeared after 2010. Compared to other Michael acceptors, the distinctive structure of acylimidazoles afforded unique reactivity through double coordination with metals. We have shown that this crucial point paved the way to improved outcomes in both reactivity and selectivity in asymmetric syntheses. Moreover, a point that should not be underestimated, the easy post-synthetic transformation of acyl-imidazoles into other carbonyl derivatives that allows further structural diversification for a myriad of applications. Given the practical features by using acylimidazoles as substrates, further developments in terms of reactivity, stability, selectivity and post-diversifications are expected to both enlarge their attractiveness and encourage their use in organic and biological chemistry. Moreover, their use in multicomponent, sequential, and cascade processes are still in their infancy and efforts on these key areas should allow for the rapid access to complex structures.

\section{Acknowledgements}

We thank the ENSCM (Ecole Nationale Supérieure de Chimie de Montpellier), ENSCR (Ecole Nationale Supérieure de Chimie de Rennes) and CNRS (Centre National de la Recherche Scientifique). Funding of our own work in this field is provided by the ANR (Agence Nationale de la Recherche) and the "Fondation pour le développement de la chimie des substances naturelles" (PhD grant of $\mathrm{JL}$ ). MM and OB thank the ANR for financial support (ANR-16-CE07-0019 "Hel-NHC" grants to DP).

Keywords: acyl-imidazoles • versatile substrates • asymmetric synthesis $\cdot$ catalysis $\cdot$ post-functionalizations

\section{Conflict of interest}

The authors declare no conflict of interest.

[1] S. Hayakawa, T. Michiue, M. Okamoto, S. Hatakeyama, S. Ohta, Heterocycles 1988, 27, 457-473.

[2] S. Ohta, S. Hayakawa, K. Nishimura, M. Okamoto, Chem. Pharm. Bull. 1987, 35, 1058-1069.

[3] A. Miyashita, Y. Suzuki, I. Nagasaki, C. Ishiguro,K.-i. Iwamoto, T. Higashino, Chem. Pharm. Bull. 1997, 45, 1254-1258.

[4] D. A. Evans, K. R. Fandrick, H.-J. Song, K. A. Scheidt, R. Xu, J. Am. Chem. Soc. 2007, 129, 10029-10041.
[5] D. A. Evans, K. R. Fandrick, H.-J. Song, J. Am. Chem. Soc. 2005, 127, 8942-8943.

[6] a) S. Drissi-Amraoui, M. Morin, C. Crévisy, O. Baslé, R. M. de Figueiredo, M. Mauduit, J.-M. Campagne, Angew. Chem. Int. Ed. 2015 54, 11830-11834; Angew. Chem. 2015, 127, 11996-12000; b) S. Drissi-Amraoui, T. E. Schmid, J. Lauberteaux, C. Crévisy, O. Baslé, R. M. de Figueiredo, S. Halbert, H. Gérard, M. Mauduit, J.-M. Campagne, Adv. Synth. Catal. 2016, 358, 2519-2540.

[7] D. A. Evans, K. R. Fandrick, Org. Lett. 2006, 8, 2249-2252.

[8] H. B. Albada, F. Rosati, D. Coquière, G. Roelfes, R. M. J. Liskamp, Eur. J. Org. Chem. 2011, 1714-1720.

[9] B. Zhang, F. Han, L. Wang, D. Li, D. Yang, X. Yang, J. Yang, X. Li, D. Zhao, R. Wang, Chem. Eur. J. 2015, 21, 17234-17238.

[10] a) M. Mauduit, O. Baslé, H. Clavier, C. Crévisy, A. Denicourt-Nowicki, in Comprehensive Organic Synthesis II, vol. 4 (eds.: P. Knochel, G. A. Molander), Elsevier, 2014, pp 186; b) For a seminal review dealing with Cu-ACA in natural product synthesis, see: B. C. Calvo, J. Buter, A. J. Minnaard, Applications to the synthesis of natural products in CopperCatalyzed Asymmetric Synthesis (Eds: A. Alexakis, N. Krause, S. Woodward) Wiley, 2014, Chapter 14, pp. 373-447.

[11] a) H. Ohmiya, M. Yoshida, M. Sawamara, Org. Lett. 2011, 13, 482; b) M. Yoshida, H. Ohmiya, M. Sawamara, J. Am. Chem. Soc. 2012, 134, 11896.

[12] X. Xu, W.-H. Hu, M. P. Doyle, Angew. Chem. Int. Ed. 2011, 50, 63926395; Angew. Chem. 2011, 123, 6516-6519.

[13] S. Rout, A. Das, V. K. Singh, Chem. Commun. 2017, 53, 5143-5146.

[14] S. Rout, A. Das, V. K. Singh, J. Org. Chem. 2018, 83, 5058-5071.

[15] D. A. Evans, H.-J. Song, K. R. Fandrick, Org. Lett. 2006, 8, 3351-3354.

[16] X. Shen, H. Huo, C. Wang, B. Zhang, K. Harms, E. Meggers, Chem Eur. J. 2015, 21, 9720-9726.

[17] B. M. Trost, T. M. Lam, J. Am. Chem. Soc. 2012, 134, 11319-11321.

[18] B. M. Trost, K. Lehr, D. J. Michaelis, J. Xu, A. K. Buckl, J. Am. Chem. Soc. 2010, 132, 8915-8917.

[19] A. J. Simpson, H. W. Lam, Org. Lett. 2013, 15, 2586-2589.

[20] X. Hou, H. Ma, Z. Zhang, L. Xie, Z. Qin, B. Fu, Chem. Commun. 2016, 52, 1470-1473.

[21] H. Ma, L. Xie, Z. Zhang, L.-g. Wu, B. Fu, Z. Qin, J. Org. Chem. 2017 82, 7353-7362.

[22] D. Yang, L. Wang, D. Li, F. Han, D. Zhao, R. Wang, Chem. Eur. J. 2015 21, 1458-1462.

[23] J. Wang, P. Wang, L. Wang, D. Li, K. Wang, Y. Wang, H. Zhu, D. Yang R. Wang, Org. Lett. 2017, 19, 4826-4829.

[24] For accounts on the use of such chiral-at-metal complexex, see: a) L. Zhang, E. Meggers, Acc. Chem. Res. 2017, 50, 320-330; b) E. Meggers, Angew. Chem. Int. Ed. 2017, 56, 5668-5675; Angew. Chem. 2017, 129, 5760-5768; c) S. Chen, X. Huang, E. Meggers, K. N. Houk, J. Am. Chem. Soc. 2017, 139, 17902-17907.

[25] H. Huo, C. Fu, K. Harms, E. Meggers, J. Am. Chem. Soc. 2014, 136, 2990-2993.

[26] C. Wang, L.-A. Chen, H. Huo, X. Shen, K. Harms, L. Gong, E. Meggers, Chem. Sci. 2015, 6, 1094-1100.

[27] V. A. Larionov, T. Cruchter, T. Mietke, E. Meggers, Organometallics 2017, 36, 1457-1460.

[28] Z. Zhou, Y. Li, L. Gong, E. Meggers, Org. Lett. 2017, 19, 222-225.

[29] J. Ma, X. Shen, K. Harmsa, E. Meggers, Dalton Trans. 2016, 45 , 8320-8323.

[30] S.-W. Li, Q. Wan, Q. Kang, Org. Lett. 2018, 20, 1312-1315.

[31] X. Ding, H. Lin, L. Gong, E. Meggers, Asian J. Org. Chem. 2015, 4, 434-437.

[32] T. Deng, G. K. Thota, Y. Lia, Q. Kang, Org. Chem. Front. 2017, 4, 573-577.

[33] S.-W. Li, J. Gong, Q. Kang, Org. Lett. 2017, 19, 1350-1353.

[34] Y. Tan, K. Harms, E. Meggers, Eur. J. Inorg. Chem. 2018, 2500-2504.

[35] For instance, see: D. Müller, A. Alexakis, Org. Lett. 2012, 14, 1842-1845. 
[36] K. Li, Q. Wan, Q. Kang, Org. Lett. 2017, 19, 3299-3302.

[37] H. Huo, K. Harms, E. Meggers, J. Am. Chem. Soc. 2016, 138, 6936-6939.

[38] Z. Zhou, Y. Li, B. Han, L. Gong, E. Meggers, Chem. Sci. 2017, 8, 5757-5763.

[39] S.-X. Lin, G.-J. Sun, Q. Kang, Chem. Commun. 2017, 53, 7665-7668.

[40] W. Yuan, Z. Zhou, L. Gong, E. Meggers, Chem. Commun. 2017, 53, 8964-8967.

[41] F. F. de Assis, X. Huang, M. Akiyama, R. A. Pilli, E. Meggers, J. Org. Chem. 2018, 83, 10922-10932.

[42] G.-J. Sun, J. Gong, Q. Kang, J. Org. Chem. 2017, 82, 796-803.

[43] E. L. Tyson, E. P. Farney, T. P. Yoon, Org. Lett. 2012, 14, 1110-1113.

[44] X. Huang, T. R. Quinn, K. Harms, R. D. Webster, L. Zhang, O. Wiest, E. Meggers, J. Am. Chem. Soc. 2017, 139, 9120-9123.

[45] Y. Huang, L. Song, L. Gong, E. Meggers, Chem. Asian J. 2015, 10, 2738-2743.

[46] H. Huo, X. Shen, C.Wang, L. Zhang, P. Röse, L.-A. Chen, K. Harms, M. Marsch, G. Hilt, E. Meggers, Nature 2014, 515, 100-103.

[47] H. Huo, C. Wang, K. Harms, E. Meggers, J. Am. Chem. Soc. 2015, 137, 9551-9554.

[48] H. Huo, X. Huang, X. Shen, K. Harms, E. Meggers, Synlett 2016, 27, 749-753.

[49] C. Wang, Y. Zheng, H. Huo, P. Röse, L. Zhang, K. Harms, G. Hilt, E. Meggers, Chem. Eur. J. 2015, 21, 7355-7359.

[50] Y. Tan, W. Yuan, L. Gong, E. Meggers, Angew. Chem. Int. Ed. 2015, 54, 13045-13048; Angew. Chem. 2015, 127, 13237-13240.

[51] X. Huang, R. D. Webster, K. Harms, E. Meggers, J. Am. Chem. Soc. 2016, 138, 12636-12642.

[52] X. Shen, K. Harms, M. Marsch, E. Meggers, Chem. Eur. J. 2016, 22, 9102-9105.

[53] J. Ma, A. R. Rosales, X. Huang, K. Harms, R. Riedel, O. Wiest, E. Meggers, J. Am. Chem. Soc. 2017, 139, 17245-17248.

[54] X. Zhang, J. Qin, X. Huang, E. Meggers, Eur. J. Org. Chem. 2018, 571-577.

[55] G.-Q. Xu, H. Liang, J. Fang, Z.-L. Jia, J.-Q. Chen, P.-F. Xu, Chem. Asian J. 2016, 11, 3355-3358.
[56] H. Lin, Z. Zhou, J. Cai, B. Han, L. Gong, E. Meggers, J. Org. Chem. 2017, 82, 6457-6467.

[57] L. Feng, X. Dai, E. Meggers, L. Gong, Chem. Asian J. 2017, 12, 963-967.

[58] J. Gong, S.-W. Li, S. Qurban, Q. Kang, Eur. J. Org. Chem. 2017, 3584-3593.

[59] G. K. Thota, G.-J. Sun, T. Deng, Y. Li, Q. Kang, Adv. Synth. Catal. 2018, 1094-1098.

[60] M. B. Andrus, M. A. Christiansen, E. J. Hicken, M. J. Gainer, D. K Bedke, K. C. Harper, S. R. Mikkelson, D. S. Dodson, D. T. Harris, Org Lett. 2007, 9, 4865-4868.

[61] M. A. Christiansen, A. W. Butler, A. R. Hill, M. B. Andrus, Synlett 2009, 4, 653-657.

[62] M. A. Christiansen, M. B. Andrus, Tetrahedron Lett. 2012, 53, 4805-4808

[63] M. Uyanik, H. Okamoto, T.Yasui, K. Ishihara, Science 2010, 328 1376-1379.

[64] M. Uyanik, H. Hayashi, H. Iwata, K. Ishihara, Chem. Lett. 2016, 45, 353-355.

[65] M. Uyanik, H. Hayashi, K. Ishihara, Science 2014, 345, 291-294.

[66] M. Uyanik, D. Suzuki, T. Yasui, K. Ishihara, Angew. Chem. Int. Ed. 2011, 50, 5331-5334; Angew. Chem. 2011, 123, 5443-5446.

[67] M. Uyanik, K. Ishihara, ChemCatChem 2012, 4, 177-185.

[68] J.-L. Shih, T. S. Nguyen, J. A. May, Angew. Chem. Int. Ed. 2015, 54 9931-9935; Angew. Chem. 2015, 127, 10069-10073.

[69] O. Quinonero, M. Jean, N. Vanthuyne, C. Roussel, D. Bonne, T Constantieux, C. Bressy, X. Bugaut, J. Rodriguez, Angew. Chem. Int. Ed. 2016, 55, 1401-1405; Angew. Chem. 2016, 128, 1423-1427.

[70] J. Gong, K. Li, S. Qurban, Q. Kang, Chin. J. Chem. 2016, 34 1225-1235.

[71] L. Song, L. Gong, E. Meggers, Chem. Commun. 2016, 52, 7699-7702.

[72] S. Qurban, J. Gong, Y. Du, Q. Kang, Org. Chem. Front. 2018, 5 2870-2874

[73] X.-Y. Guan, L.-P. Yang, W. Hu, Angew. Chem. Int. Ed. 2010, 49, 21902192; Angew. Chem. 2010, 122, 2236-2238.

[74] J. Mansot, J.-J. Vasseur, S. Arseniyadis, M. Smietana, ChemCatChem 2019, 10.1002/cctc. 201900743 


\section{Entry for the Table of Contents (Please choose one layout)}

Layout 1:

\section{REVIEW}

Since their first use in asymmetric Friedel-Crafts reactions, acylimidazoles have appeared as powerful ester/amide surrogates. Indeed, the imidazole moiety displays stability and special activation features that allow enhanced reactivity and selectivity in traditional ester/amide functionalization. An overview of the contemporary and growing interest for acyl-imidazoles in metal- and organocatalyzed transformations, as well as post-functionalization expediencies will be highlighted.
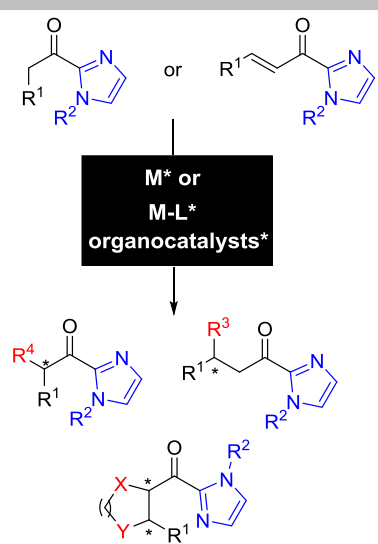

$\alpha-, \beta-, \alpha, \beta-, \gamma$-functionalizations
Jimmy Lauberteaux, Delphine Pichon, Olivier Baslé, Marc Mauduit, Renata Marcia de Figueiredo, * and Jean-Marc Campagne*

Page No. - Page No.

Acyl-Imidazoles: A Privileged Ester Surrogate for Enantioselective 